Published in : Chemistry - A European Journal, vol. 7, num. 3, p. 600-610

Copyright: Wiley-VCH

\title{
Molecular dynamics simulations of MRI-relevant Gd(III) chelates: direct access to outer-sphere relaxivity [postprint version]
}

\author{
Alain Borel, Lothar Helm and André E. Merbach*[a] \\ ${ }^{\text {[a] }}$ Prof. A. E. Merbach, A. Borel, Dr. L. Helm \\ Institut de Chimie Minérale et Analytique, Université de Lausanne, BCH \\ CH-1015 Lausanne, Switzerland \\ * Author to whom correspondence should be addressed

\section{Graphical Abstract}

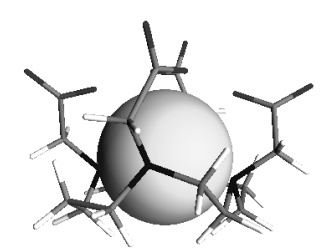

Molecular dynamics simulations have been performed in order to study the outer hydration shell structure and dynamics around Gd(III) chelates. The prediction of a very fast electron spin relaxation for $[\mathrm{Gd}(\mathrm{TETA})]^{-}$, confirmed by EPR measurements, was an unexpected result of the analysis of our simulations.

Correspondence to:

André E. Merbach

Institute of Inorganic and Analytical Chemistry, University of Lausanne, BCH CH-1015 Lausanne, Switzerland

Fax : +41-21-692 3875 ; e-mail : andre.merbach@icma.unil.ch 


\begin{abstract}
Molecular dynamics simulations were carried out for several Gd(III) polyaminocarboxylate and polyaminophosphonate complexes in aqueous solution to study the structure and dynamics of surrounding water. The radial distribution functions (rdf) show that a few water molecules bind to the ligand through hydrogen bonds to hydrophilic groups such as carboxylates and phosphonates. Residence times are on the order of $20-25$ ps for the polyaminocarboxylate and $56 \mathrm{ps}$ for the polyaminophosphonate chelates. No preferred orientation or binding of water molecules is observed in the hydrophobic region of the anisotropic macrocyclic complexes. Our rdf allow the calculation of the outer-sphere contribution to the nuclear magnetic resonance dispersion (NMRD) profiles using Freed's finite differences method including electronic relaxation. The results show that the commonly used analytical force-free model is only an empirical relationship. When experimental outersphere NMRD profiles are available ([Gd(TETA) $]^{-}$and $\left.[\mathrm{Gd}(\mathrm{DOTP})]^{5-}\right)$ the calculated curves are in a good agreement. In the case of [Gd(TETA) $]^{-}$, the comparison with the experimental NMRD profile has lead us to predict a very fast electronic relaxation, which has been confirmed by the EPR spectrum.
\end{abstract}

Keywords: Molecular dynamics - Chelates - Gadolinium - Outer-sphere Relaxivity - MRI 


\section{Introduction}

Gd(III) complexes are routinely used as contrast agents in Magnetic Resonance Imaging (MRI). Contrast improvement is a consequence of the enhancement of the water proton magnetic relaxation rate in tissues through interactions with the 7 unpaired $\mathrm{f}$ electrons of the $\mathrm{Gd}(\mathrm{III})$ center. The relaxation rate enhancement at a fixed $\left[\mathrm{Gd}^{3+}\right]=1 \mathrm{mM}$ concentration (relaxivity) is commonly divided into two contributions, namely inner-sphere (due to protons of water molecules directly coordinated to the metal and transmitted to the bulk by chemical exchange) and outer-sphere relaxivity (dipolar interactions through space with surrounding water molecules). ${ }^{[1,2]}$ While the former is well understood on the microscopic scale, the latter is usually described using an approximate force-free model by Freed ${ }^{[3,4]}$ where the only parameters are the relative diffusion coefficient between the paramagnetic center and water molecules, and the distance of closest approach for the protons. Recently, this simple division has been questioned in several studies ${ }^{[5,6]}$ with the introduction of a so-called second coordination sphere. To obtain a more detailed view, we have used molecular dynamics simulations to study the structure and dynamics of water around several Gd(III) complexes: three with macrocyclic ligands, [Gd(TETA) $]^{-}\left(\right.$TETA $=\mathrm{N} \mathrm{N}^{\prime}, \mathrm{N}^{\prime}, \mathrm{N}^{\prime \prime}$-tetracarboxymethyl1,4,8,11-tetraazacyclotetradecane $), \quad\left[\mathrm{Gd}(\mathrm{DOTA})\left(\mathrm{H}_{2} \mathrm{O}\right)\right]^{-} \quad\left(\right.$ DOTA $\quad=\quad \mathrm{N}, \mathrm{N}^{\prime}, \mathrm{N}^{\prime \prime}, \mathrm{N}^{\prime \prime}-$ tetracarboxymethyl-1,4,7,10-tetraazacyclododecane), and $\quad[\operatorname{Gd}(\mathrm{DOTP})]^{5-} \quad(\mathrm{DOTP}=$ $\mathrm{N}, \mathrm{N}^{\prime}, \mathrm{N}^{\prime}, \mathrm{N}$ '"-tetraphosphononatomethyl-1,4,7,10-tetraazacyclododecane), and two with acyclic ligands $\left[\mathrm{Gd}(\mathrm{DTPA})\left(\mathrm{H}_{2} \mathrm{O}\right)\right]^{2-}\left(\mathrm{DTPA}=\mathrm{N}, \mathrm{N}, \mathrm{N}^{\prime}, \mathrm{N}^{\prime \prime}, \mathrm{N}^{\prime \prime}-\right.$ pentacarboxymethyl-1,4,7triazapentane), and $\quad\left[\mathrm{Gd}(\mathrm{DTPA}-\mathrm{BMA})\left(\mathrm{H}_{2} \mathrm{O}\right)\right] \quad($ DTPA-BMA $\quad=\quad \mathrm{N}, \mathrm{N}$ "-bis $[(\mathrm{N}-$ methylcarbamoyl)methyl)]-N,N',N"-triscarboxymethyl-1,4,7-triazapentane) (Figure 1). Two of these complexes, namely $[\mathrm{Gd}(\mathrm{TETA})]^{-}$and $[\mathrm{Gd}(\mathrm{DOTP})]^{5-}$ have no inner sphere water, allowing direct experimental study of the outer sphere relaxivity. Comparison of the 
theoretical and experimental results for these two compounds is therefore an important step in the understanding of MRI contrast agents relaxivity beyond the inner sphere.

This work is part of an ongoing effort to study the properties of transition metal and lanthanide ions and their complexes in aqueous solution using computational methods. Earlier systems studied in our group include molecular dynamics simulations of trivalent lanthanide ions ${ }^{[7-9]}$ and the chromium(III) heaxaaqua complex.. ${ }^{[10]}$ In all these systems, the existence of a labile coordination sphere (first sphere for the lanthanides, second sphere for chromium) was well established by experimental methods such as ${ }^{17} \mathrm{O}-\mathrm{NMR}$ and the agreement between experimental and computational results was found to be fairly good. No direct structural and dynamic data is available for the outer sphere MRI contrast agents and related complexes. Our goal was to obtain such information through classical molecular dynamics simulations.

The determination of the properties of potential MRI contrast agents often ends up with the measurement of the final quantity of interest, namely the total relaxivity $r_{1}$ itself. As it stands, Freed's force-free model has been an important tool to estimate the outer-sphere contribution to relaxivity. So the aim of our study is not only to confirm or infirm the validity of this model, but also to try and calculate the outer-sphere relaxivity contribution directly from our simulations.

Computer modeling has been used in the past to investigate the properties of gadolinium MRI contrast agents. Molecular mechanics, ${ }^{[11-13]}$ Hartree-Fock $\left.{ }^{[14,} 15\right]$ and density functional theory ${ }^{[16]}$ have been applied, generally with an emphasis on the structure and energy of these compounds. In this study we are interested in the interaction of these complexes with surrounding water molecules so the main goal of our force field will be the description of intermolecular forces using ad hoc parameters derived from ab initio calculations.

\section{Simulation outline}




\section{Force field parameters}

A proper description of the electrostatic potential is essential to simulations involving ions and polar molecules. To achieve this goal we calculated partial atomic charges for the various complexes using the Merz-Kollman method ${ }^{[17]}$ as implemented in the Gaussian94 package. ${ }^{[18]}$ This method outputs atomic charges by fitting them to the electrostatic potential at a fixed distance through a dielectric medium. Ab initio calculations were performed on the four available crystal structures ${ }^{[19-22]}$ at the $6-31 \mathrm{G}^{* *}$ level $(\mathrm{H}, \mathrm{C}, \mathrm{N}, \mathrm{O}, \mathrm{P})$ with pseudopotentials by Stoll and Savin ${ }^{[23]}$ accounting for relativistic corrections in the treatment of the core electrons of $\mathrm{Gd}$. The calculated charges were then averaged on all the atoms of a same type. The calculated charges and atom types are reported in Table 1. For the $[\mathrm{Gd}(\mathrm{DOTP})]^{5-}$ complex, no experimental crystal structure was available, so we calculated an optimized structure (see Table 2) using the DFT program ADF.[24] This calculation was performed at the NLDA level with Becke ${ }^{[25]}$ and Perdew ${ }^{[26]}$ gradients for the exchange and correlation functionals. The basis set was STO with triple zeta and polarization, using the smallest possible core for each element (O, C, N: He core; P: Ne core; Gd: Xe core).

The Merz-Kollman approach leads to a good representation of the electrostatic potential at the molecular surface but only to a rather poor description of intramolecular electrostatic interactions. In our systems, the bonding of negatively charged donor groups such as carboxylates, and inner-sphere water to the metal center was found to be especially problematic. To avoid undesired behavior during the simulation (such as the substitution of a carboxylate group by solvent molecules or departure of the inner-sphere water molecule) we introduced bonds with crystallographic length for the Gd(III) coordination. We can justify this treatment because the complexes can be considered rigid on the MD time scale. Using ${ }^{17} \mathrm{O}$ NMR, Powell et al.[27] found that inner-sphere residence time of water molecules was in the order of microseconds for the fastest exchanging complexes in our study, $\left[\mathrm{Gd}(\mathrm{DOTA})\left(\mathrm{H}_{2} \mathrm{O}\right)\right]^{-}$ 
and $\left[\mathrm{Gd}(\mathrm{DTPA})\left(\mathrm{H}_{2} \mathrm{O}\right)\right]^{2-}$. The $\left[\mathrm{Gd}(\mathrm{DOTA})\left(\mathrm{H}_{2} \mathrm{O}\right)\right]^{-}$complex is present in solution as a mixture of a major $M(80 \%)$ and a minor $m(20 \%)$ isomer with different structures.[28] We used the $M$ isomer structure, which we may also consider a rigid molecule as the exchange rate between the isomers is slow throughout the lanthanide series even on the ${ }^{1} \mathrm{H}-\mathrm{NMR}$ time scale.

We used the TIP3P model of Jorgensen et al.[29] for water molecules. Van der Waals parameters for $\mathrm{Gd}^{3+}$ were those published by Kowall et al. ${ }^{[7-9]}$ Other parameters for the force field were taken from the GROMOS86 ${ }^{[30]}$ package.

\section{Computation details}

Molecular dynamics runs were performed in the NTP ensemble using the GROMOS86 program running on a Silicon Graphics workstation. Bond lengths for all molecules in the system were fixed by the SHAKE procedure, ${ }^{[31]}$ temperature and pressure were conserved using the algorithm of Berendsen. ${ }^{[32]}$ For each system the solute molecule was immersed in an initial $25 \times 25 \times 25 \AA^{3}$ cubic periodic box $\left(35 \times 35 \times 35 \AA^{3}\right.$ for the highly charged $[\text { Gd(DOTP) }]^{5-}$ complex). No counterions were included in the simulation. Although this might be inappropriate for the complexes with a high negative charge, this makes the analysis easier and more systematic when comparing complexes with different ligands. Other important parameters are summarized in Table 3.

\section{Complexes with macrocyclic ligands}

\section{Structural results}

In this section we present structural results for complexes with macrocyclic ligands (TETA ${ }^{4-}$, DOTA $^{4-}$, and DOTP $\left.{ }^{8-}\right)$. The radial distribution function $g(r)(\mathrm{rdf})$ is calculated as an average over the simulation configurations as the quotient of the local density of a given particle (in 
our case water molecules given by their oxygen or hydrogen atoms) at distance $r$ from a given center (for example the Gd(III) ion) by the overall density [Eq. (1)].

$$
g(r)=\frac{n(r)}{4 \pi r^{2} \Delta r \rho}
$$

Figure 2 displays the gadolinium-solvent water radial distribution function $g(r)$ as given by water oxygen and hydrogen atoms respectively. In the case of $\left[\mathrm{Gd}(\mathrm{DOTA})\left(\mathrm{H}_{2} \mathrm{O}\right)\right]^{-}$, the inner sphere water molecule is excluded from this distribution since its distance to the metal is constrained in the simulations. For all complexes, both $\mathrm{Gd}-\mathrm{H}$ and $\mathrm{Gd}-\mathrm{O}$ rdf's display a rather well-defined peak in the $3.0 \AA$ A to $5.0 \AA$ A region (see Table 4), which shows that water between these distances has a distinct behavior from the bulk water. Relative positions of the $\mathrm{H}$ and $\mathrm{O}$ peaks indicate that water hydrogens are involved in bonding to the solute molecule. By integrating $g(r)$ from 0 to the first minimum of the curve, we can define coordination numbers $q_{O}$ and $q_{H}$ for the second coordination shell oxygens and hydrogens respectively. As can be seen from Table 4 , this number is too small $\left(q_{o}=2\right.$ to 5$)$ to encompass the whole complex with a complete hydration sphere. Therefore a more detailed analysis is required.

The axial symmetry of the $[\mathrm{Gd}(\mathrm{TETA})]^{-},\left[\mathrm{Gd}(\mathrm{DOTA})\left(\mathrm{H}_{2} \mathrm{O}\right)\right]^{-}$and $[\mathrm{Gd}(\mathrm{DOTP})]^{5-}$ complexes allows us to divide space around the complex into two regions, one hydrophilic (containing the carboxylates/phosphonates) and one hydrophobic (containing the macrocycle) as in Figure 3. The dividing plane is perpendicular to the main rotation axis, which can be adequately described by the vector joining the Gd(III) ion and the center of mass of the eight carboxylate oxygens. Thus we can distinguish water molecules in both regions and observe possible differences between them. We calculate the partial rdf in both in the hydrophilic (carboxylates/phosphonates) and the hydrophobic (azacycle) regions. As shown on Figure 4, the water molecules responsible for the hydration peak are only located in the 
carboxylates/phosphonates hemisphere of the complexes. Binding to the carboxylate/phosphonate oxygens is confirmed by the $\mathrm{rdf}$ around these atoms (Figure 5). A sharp peak of both the oxygen and hydrogen rdf is observed (with a maximum at $r=1.6 \AA$ for $\mathrm{H}$ and $r=2.6 \AA$ for $\mathrm{O}$ ). The closer $\mathrm{H}$ peak is indicative of hydrogen bonds between water and the carboxylate oxygens. The free carboxylate oxygens $\mathrm{O}_{\mathrm{f}}$ are more accessible to the water hydrogens than their coordinated counterparts $\mathrm{O}_{c}$, so they give rise to a higher number of hydrogen bonds and to a consequently higher rdf peak. On the other hand no preferred orientation is apparent around the less accessible nitrogens of the cycle. The graph of $g(r)$ rises smoothly from 0 to 1 at a distance of about $4 \AA$, indicative of a shielding of the nitrogen atoms by the sheer volume of the neighboring macrocyclic $\mathrm{C}$ and $\mathrm{H}$, and there is essentially no difference between the $\mathrm{H}$ and $\mathrm{O}$ distributions. The $\left[\mathrm{Gd}(\mathrm{DOTA})\left(\mathrm{H}_{2} \mathrm{O}\right)\right]^{-}$and $[\mathrm{Gd}(\mathrm{DOTP})]^{5-}$ complexes display the same features, so they won't be discussed in more detail.

Binding of water molecules through their hydrogens can also be shown by their dipole orientation, characterized by the cosine of the angle between the $\mathrm{Gd}-\mathrm{O}$ vector and the water dipole as shown on Figure 6. As can be seen by the plot of the average cosine of the GdO/dipole angle $\Theta$ (Figures 7 and 8 ), water molecules close to the metal center $\left(r_{G d O}<5 \AA\right.$ ) are preferably oriented with one or both of their hydrogens toward the complex core $(\cos \Theta$ close to -1 , and the angle distribution remains narrow). At a larger distance water molecules are randomly oriented (the average $\cos \Theta$ is nearly zero and the distribution broadens as shown by its standard deviation). This is coherent with the bonding of water protons to carboxylate/phosphonate oxygen. One can observe that for $[\mathrm{Gd}(\mathrm{DOTP})]^{5-}$, the curve rises again to less negative values of $\cos \Theta$ when the metal-oxygen distance diminishes. The closest approach distance during the simulation was $r_{G d O}=2.76 \AA$ for this complex, only 0.3 $\AA$ A longer than the inner sphere $r_{G d O}$ distance in $\left[\mathrm{Gd}(\mathrm{DOTA})\left(\mathrm{H}_{2} \mathrm{O}\right)\right]^{-}$. The graph of oxygen $g(r)$ (Figure 2a) also supports the picture of one water molecule in the close vicinity of the metal 
as shown by the shoulder of the curve in the 2.5-3.5 $\AA$ region. However this was a very rare event as only $0.2 \%$ of the stored configurations show a water molecule closer than $2.9 \AA$ from the metal. Incidentally the integration of $g(r)$ from 0 to $3.5 \AA$ only corresponds to 0.4 water oxygen atoms. Speaking of the coordination of one inner-sphere water molecule would be too strong in this case considering the uniqueness of the event.

\section{Dynamic properties}

Water molecules located in the second coordination shell will typically exchange with molecules from the bulk after an average residence time $\tau_{M}$. This residence time can be calculated from the persisting coordination correlation function $n(t)^{[33]}$ [Eq. (2)]

$$
n(t)=\frac{1}{N} \sum_{i=1}^{N} \sum_{j} P_{j}\left(t_{n}, t, t^{*}\right)
$$

where $P_{j}$ is equal to one if water molecule $j$ is in the coordination shell (defined in our case by the first minimum of the Gd-O rdf at $5.0 \AA$ as an outer limit) at times $t_{n}$ and $t_{n}+t$ and is only allowed to leave this shell for small delays shorter than $t^{*}$. One can assume a decaying exponential form for this correlation function [Eq. (3)].

$$
n(t) \cong q \exp \left(\frac{-t}{\tau_{M}}\right)
$$

By fitting Eq. (3) to the calculated $n(t)$, one obtains the coordination number $q$ and the residence time $\tau_{M}$. However, the result depends on $t^{*}$ and should increase monotonically with this parameter. We used a canonical value for $t^{*}$ of 2 ps. ${ }^{[33]}$ The calculated parameters and the errors from the fit are given in Table 5.

Obtained residence times for $\mathrm{H}_{2} \mathrm{O}$ molecules in our second coordination shell are in the 20-25 ps range for the polyaminocarboxylate complexes (56 ps for the polyaminophosphonate-based $[\operatorname{Gd}(\mathrm{DOTP})]^{5-}$, indicating a fast exchange with bulk water: as a comparison the second- 
sphere residence time of water molecules around the inert $\left[\mathrm{Cr}\left(\mathrm{H}_{2} \mathrm{O}\right)_{6}\right]^{3+}$ complex has been determined both experimentally through ${ }^{17} \mathrm{O}-\mathrm{NMR}$ and theoretically through MD simulations to be over $120 \mathrm{ps},{ }^{[10]}$ whereas the simulations of Kowall et al. ${ }^{[9]}$ showed a residence time of 12, 13 and $18 \mathrm{ps}$ in the second shell of $\mathrm{Sm}^{3+}, \mathrm{Nd}^{3+}$ and $\mathrm{Yb}^{3+}$, respectively. However, our values should be compared with these results only with extreme caution, as the hydrogen bonding of solvent water molecules to the complex proceeds through water oxygens in these aqua complexes. Our residence times are more properly compared to other results obtained for organic (such as organic solvents: 4.8 ps for DMSO in a 1:2 DMSO-water mixture ${ }^{[34]}$ ) and biological molecules (3.9 to $7.7 \mathrm{ps}$ on the alanine dipeptide, ${ }^{[35]} 10$ to 15 ps for ribose and phosphate oxygens on the trp operator double-stranded DNA fragment $\left.{ }^{[36,37]}\right)$.

One could criticize the metal-centric second shell definition we have given. Indeed it is quite possible to take another definition for the presence function $P_{j}$ (see Eq. (2)). If we study the presence of water hydrogens around carboxylate or phosphonate oxygens we will obtain the mean lifetime of hydrogen bonds between the complex and solvent molecules. As before we can distinguish Gd-bound carboxylate/phosphonate oxygens and free oxygens. The distance limit is fixed to $r_{O H}=2.2 \AA$.

Hydrogen bonds lifetimes (Table 6) are shorter than the mean residence times in the second coordination shell. This can be explained by the possibility for water molecules to jump from one donor oxygen to another without leaving the second coordination shell. Indeed we observe a rather high frequency of water molecules (Table 7) simultaneously hydrogenbonded to two carboxylate/phosphonate oxygens. For the free oxygens $\mathrm{O}_{\mathrm{f}}$, the ability to bind to more water molecules than the coordinating oxygen $\mathrm{O}_{\mathrm{c}}$ (hydration number $q_{f}>q_{c}$ ) is balanced with a greater lability (the hydrogen bond lifetime is shorter).

\section{Complexes with acyclic ligands}




\section{Structural results}

Unlike their macrocycle-derivative counterparts the acyclic ligand complexes $\left[\mathrm{Gd}(\mathrm{DTPA})\left(\mathrm{H}_{2} \mathrm{O}\right)\right]^{2-}$ and $\left[\mathrm{Gd}(\mathrm{DTPA}-\mathrm{BMA})\left(\mathrm{H}_{2} \mathrm{O}\right)\right]$ do not have the benefit of high symmetry. Therefore only average values over the whole space are presented for the radial distribution around the $\mathrm{Gd}^{3+}$ ion (Figure 9). We observe the same general features as for the macrocyclic compounds: the position of the first peak of the $\mathrm{H}$ rdf is closer to the metal than the one of the $\mathrm{O}$ rdf. However the average number of water molecules present in the second coordination shell (Table 4) is higher than for the [Gd(TETA) $]^{-},\left[\operatorname{Gd}(\text { DOTA })\left(\mathrm{H}_{2} \mathrm{O}\right)\right]^{-}$and $[\mathrm{Gd}(\mathrm{DOTP})]^{5-}$ complexes, coherent with a more extended binding site. Indeed the hydrophilic part of the complex is proportionally larger for the acyclic complexes. The ligand occupies 8 sites in the capped square antiprism geometry, five of which are used by carboxylate/amide oxygens in the acyclic ligands (compared to only four in the macrocyclic ligands). One finds a higher value of the second-shell coordination number for the doubly charged $\left[\operatorname{Gd}(\mathrm{DTPA})\left(\mathrm{H}_{2} \mathrm{O}\right)\right]^{2-}$ than for the neutral [Gd(DTPA-BMA) $\left.\left(\mathrm{H}_{2} \mathrm{O}\right)\right]$.

\section{Influence of the inner-sphere water molecule on the second coordination shell}

Since the dipole orientation of the second coordination shell water is rather opposite to the one of the inner-sphere water molecule, one may wonder about the interaction of the latter with water molecules belonging to the second shell. The radial distribution of solvent water around the inner sphere water protons (Figure 10) shows a peak near $2.0 \AA$, with a following minimum at $2.3 \AA$. The height of the peak depends on the ligand: it is rather strong for the $\left[\mathrm{Gd}(\mathrm{DTPA})\left(\mathrm{H}_{2} \mathrm{O}\right)\right]^{2-}$ complex, but almost disappears with [Gd(DTPA-BMA $\left.)\left(\mathrm{H}_{2} \mathrm{O}\right)\right]$ and only a shoulder is observable for $\left[\mathrm{Gd}(\mathrm{DOTA})\left(\mathrm{H}_{2} \mathrm{O}\right)\right]^{-}$. We calculated the occurrence of hydrogen bonds between the inner sphere water molecule and the solvent using a geometrical definition. 
Besides a distance criterion $r_{\text {His-Osolvent }}<2.3 \AA$ given by the first minimum of the rdf of solvent

$\mathrm{O}$ around the inner-sphere water $\mathrm{H}$, a further angular condition $\theta_{\text {Ois-His-Osolvent }}<30^{\circ}$ was required to define a hydrogen bond ${ }^{[34,38]}$ (see Figure 11). The results show that inner-sphere water indeed interacts with the second shell water molecules, since 10-30\% of stored configurations (depending on the ligand) show second-shell water molecules bound to it in this way (Table 8).

\section{Dynamic results}

The dynamic hydration parameters of $\left[\mathrm{Gd}(\mathrm{DTPA})\left(\mathrm{H}_{2} \mathrm{O}\right)\right]^{2-}$ and $\left[\mathrm{Gd}(\mathrm{DTPA}-\mathrm{BMA})\left(\mathrm{H}_{2} \mathrm{O}\right)\right]$ are very similar to the one of $\left[\mathrm{Gd}(\mathrm{DOTA})\left(\mathrm{H}_{2} \mathrm{O}\right)\right]^{-}$and $[\mathrm{Gd}(\mathrm{TETA})]^{-}$. Again we find residence times of 20-25 ps with respect to the metal center ion (Table 5), and around 10 ps for the hydrogen bond lifetimes (Table 6).

The similarity of macrocyclic and acyclic ligand chelates in this respect allows us to make a preliminary conclusion. A second coordination shell involving a small number of water molecules in fast exchange (20-30 ps residence time) with the bulk water seems to be a general feature of gadolinium (and probably other lanthanides) polyaminocarboxylates. Ligands of this type only appear to differ in the number of water molecules involved. However, the example of $[\mathrm{Gd}(\mathrm{DOTP})]^{5-}$ shows that modifying the functional groups of the ligand can produce significant changes in the residence time of water molecules in the second coordination shell.

\section{Calculation of the outer sphere relaxivity from MD simulations}

Outer-sphere relaxivity of ${ }^{1} \mathrm{H}$ spins is usually described using the analytical force-free model of Freed, ${ }^{[3,4]}$ assuming a free relative diffusion of water molecules in the neighborhood of the 
paramagnetic center. In the light of the MD results presented so far this assumption is not valid for our systems. What we need to do is to check the consequences of this apparently invalid approximation, and to compare the simulations predictions with the experimental data obtained so far.

Freed's general translational diffusion model uses the standard equation given by Abragam ${ }^{[39]}$ for the dipole-dipole relaxation of a nuclear spin $I$ interacting with an electronic spin $S$ [Eq. (4)] and calculates spectral density functions $J(\omega)$ from the Smoluchowski diffusion equation [Eq. (5)].

$$
\begin{gathered}
\frac{1}{T_{1 d d}}=\frac{4}{15} \pi S(S+1) \gamma_{I}^{2} \gamma_{e}^{2} \hbar^{2}\left(\frac{\mu_{0}}{4 \pi}\right)^{2} N_{A} \frac{\left[G d^{3+}\right]}{1000}\left\{3 J_{0}(\omega)+7 J_{1}(\omega)\right\} \\
\frac{\partial P\left(r_{0} \mid r, t\right)}{\partial t}=D \nabla \cdot\left[\nabla P\left(r_{0} \mid r, t\right)+\frac{1}{k T} P\left(r_{0} \mid r, t\right) \nabla U(r)\right]
\end{gathered}
$$

In order to calculate the spectral density functions $J(\omega)$, one uses Abragam's time-correlation function [Eq. (6)].

$$
\begin{aligned}
& G(t)=\frac{4}{15} \Pi \int d^{3} r \int d^{3} r_{0} D_{0 m}^{(2)}\left(\Omega_{r}\right) \quad D_{0 m}^{(2)}\left(\Omega_{r_{0}}\right) P\left(r_{0} \mid r, t\right) g\left(r_{0}\right) / r_{0}{ }^{3} r^{3} \\
& J(\omega)=2 \operatorname{Re} \int_{0}^{\infty} e^{i \omega t} G(t) d t
\end{aligned}
$$

The potential of mean force $U(r)$ between two particles is related to the radial distribution function through Eq. (7).

$$
\ln g(r)=-\frac{U(r)}{k T}
$$

Thus intermolecular forces can be taken into account for arbitrary radial distributions. However an analytical form of $J(\omega)$ can only be obtained for the simplest models, like free diffusion. This is the approximation made by Freed in the now widely used force-free model. In the general case it is possible to perform a numerical calculation based on finite difference 
methods. Instead of a continuous diffusion as described by the Smoluchowski equation, let us consider a succession of finite jumps between discrete distances $r_{i}$. One can then reformulate the problem of evaluating $J(\omega)$ as in Eqs. (8) and (9). ${ }^{[4]}$

$$
\begin{gathered}
{\left[-\mathbf{W}+\mathbf{B}-1 / T_{i e} \mathbf{1}-i \omega \mathbf{1}\right] \vec{Q}=\vec{R}} \\
J(\omega)=2 \Pi \sum_{i=0}^{N} \frac{\Delta r_{i}}{r_{i}^{2}} \operatorname{Re}\left(Q_{i}\right)
\end{gathered}
$$

where $\Pi$ is the average number density. The matrix equation given by Hwang and Freed ${ }^{[4]}$ does not include the electron relaxation rate $1 / T_{i e}$, but comparison of the derivations of the analytical equations with and without this contribution leads straightforwardly to Eq. (8). The elements of the various matrices and vectors are given by Eqs. (10) and (11)

$$
\begin{gathered}
R_{i}=g\left(r_{i}\right) / r_{i}^{2} \\
B_{i j}=\delta_{i j} 6 D / r_{i}^{2}
\end{gathered}
$$

where $D$ is the diffusion coefficient $\left(22.36 \times 10^{-9} \mathrm{~m}^{-2} \mathrm{~s}^{-1}\right.$ for water at room temperature $\left.{ }^{[40]}\right)$. W is the transition probability matrix between discrete values of the distance $r$, whose elements include free diffusion and the force derived from the potential $U(r) .{ }^{[4]}$ Thus if the average diffusion coefficient and electron relaxation rate are known, calculation of the spectral distribution function $J(\omega)$ from the radial distribution function $g(r)$ is simply a matter of solving the matrix equation (8) to find the elements of $Q(r)$. Continuous variation of $\omega$ then leads to the calculation of the nuclear magnetic relaxation rate $1 / T_{1}$ as a function of the observation frequency, that is the nuclear magnetic resonance dispersion (NMRD) profile. Besides the structural information provided by the rdf one also needs to know the electronic relaxation rate $1 / T_{i e}$ as a function of the observation frequency $\omega$. In the last few years several equations have been proposed which try to account for the electronic relaxation of $\mathrm{Gd}(\mathrm{III})$ 
chelates, ${ }^{[41-45]}$ with varying success. In the following calculations we used the approach and parameters of Powell et al.,[27] where simplified expressions provide an adequate description of the electron relaxation [Eqs. (12) and (13)] and spin rotation [Eq. (14)] contributions to the ${ }^{1} \mathrm{H}$ and ${ }^{17} \mathrm{O}$ nuclear magnetic relaxation of these complexes.

$$
\begin{gathered}
\frac{1}{T_{2 e}}=\Delta^{2} \tau_{v}\left(\frac{5.26}{1+0.372 \omega_{e}^{2} \tau_{v}^{2}}+\frac{7.18}{1+1.24 \omega_{e} \tau_{v}}\right) \\
\frac{1}{T_{1 e}}=\frac{1}{25} \Delta^{2} \tau_{v}\{4 S(S+1)-3\}\left(\frac{1}{1+\omega_{e}^{2} \tau_{v}^{2}}+\frac{4}{1+4 \omega_{e}^{2} \tau_{v}^{2}}\right) \\
\frac{1}{T_{e S R}}=\frac{\delta g^{2}}{9 \tau_{R}}
\end{gathered}
$$

These equations have clear weaknesses as stated by Powell et al., but they have the advantage of a relative simplicity.

A custom program (available upon request) based on Eqs. (4) to (13) was developed for the calculation of the outer-sphere relaxivity from the rdf and electron relaxation equations. The electronic parameters are reported in Table 9. For $\left[\mathrm{Gd}(\text { DOTA })\left(\mathrm{H}_{2} \mathrm{O}\right)\right]^{-},\left[\mathrm{Gd}(\mathrm{DTPA})\left(\mathrm{H}_{2} \mathrm{O}\right)\right]^{2-}$ and $\left[\mathrm{Gd}(\mathrm{DTPA}-\mathrm{BMA})\left(\mathrm{H}_{2} \mathrm{O}\right)\right]$ we compare our calculations with the estimated outer-sphere contribution as given by the simultaneous ${ }^{17} \mathrm{O}-\mathrm{NMR} / \mathrm{NMRD} / \mathrm{EPR}$ fitting procedure of Powell et al., where Freed's force-free model was used. Experimental room-temperature NMRD profiles are reported when no inner-sphere contribution exists ([Gd(TETA) $]^{-}$and $[$ Gd(DOTP $\left.)]^{5-}\right)$. The $[\mathrm{Gd}(\mathrm{DOTP})]^{5-}$ NMRD profile was taken from the literature, ${ }^{[46]}$ whereas [Gd(TETA) $]^{-}$was measured in-house.

The outer-sphere relaxivity profile calculated for $\left[\mathrm{Gd}(\mathrm{DOTA})\left(\mathrm{H}_{2} \mathrm{O}\right)\right]^{-}$and [Gd(DTPA-BMA) $\left.\left(\mathrm{H}_{2} \mathrm{O}\right)\right]$ using the general model compare favorably with Freed's force-free model, with the advantage that no guess of the distance of closest approach $a_{G d H}$ is required (Figure 12). Freed's analytical force-free model can be used as an empirical relationship, involving two parameters $D_{G d H}$ and $a_{G d H}$. Practically the closest approach distance $a_{G d H}$ is fixed 
to a reasonable value and the relative diffusion constant $D_{G d H}$ is adjusted. However one has to be aware that the parameters extracted from this model are only effective parameters with no direct physical meaning.

In the case of $\left[\mathrm{Gd}(\mathrm{DTPA})\left(\mathrm{H}_{2} \mathrm{O}\right)\right]^{2-}$ there is a discrepancy. Our calculated low-field relaxivity is $20 \%$ higher than the value obtained using the empirical parameters of Powell. This discrepancy can be removed by reducing the closest approach distance in the model of Powell from its typical value of $3.5 \AA$ to $3.0 \AA$. Notice that this value is significantly lower than the Gd-H distance for the first maximum of the $\operatorname{rdf}(3.4 \AA)$ and should be only be considered as an effective parameter. This may be due to the fact $\left[\mathrm{Gd}(\mathrm{DTPA})\left(\mathrm{H}_{2} \mathrm{O}\right)\right]^{2-}$ is the only compound in our study for which the rdf peak of the second shell rises well above 1 (Figures $2 b$ and 9b), corresponding to 12.8 protons in the second shell (Table 4). A significant number of protons at $r<3 \AA$ compared to [Gd(DOTA) $\left.\left(\mathrm{H}_{2} \mathrm{O}\right)\right]^{-}$and $\left[\mathrm{Gd}(\mathrm{DTPA}-\mathrm{BMA})\left(\mathrm{H}_{2} \mathrm{O}\right)\right]$ might explain the higher calculated relaxivity. The residence time of water molecules in the second shell of $\left[\mathrm{Gd}(\mathrm{DTPA})\left(\mathrm{H}_{2} \mathrm{O}\right)\right]^{2-}$ is in the same range as for the other polyaminocarboxylates, so the only apparent difference is the number of these molecules. It is possible that our simulations overestimate the second shell hydration number in this case. However, since no direct experimental data is available, it is impossible at this stage to conclude on the respective accuracy of the experimental and theoretical estimations.

Since direct experimental measurements are possible for $[\mathrm{Gd}(\mathrm{TETA})]^{-}$and $[\mathrm{Gd}(\mathrm{DOTP})]^{5-}$, they obviously require a more detailed discussion. The NMRD profile obtained for $[\mathrm{Gd}(\mathrm{TETA})]^{-}$using the $\left[\mathrm{Gd}(\mathrm{DOTA})\left(\mathrm{H}_{2} \mathrm{O}\right)\right]^{-}$electronic parameters is essentially the same as for $\left[\mathrm{Gd}(\mathrm{DOTA})\left(\mathrm{H}_{2} \mathrm{O}\right)\right]^{-}$, about twice as high as the experimental profile (Figure 13). It was only possible to reproduce the rather low [Gd(TETA) $]^{-}$relaxivity $\left(2.8 \mathrm{mM}^{-1} \mathrm{~s}^{-1}\right.$ at $\left.0.02 \mathrm{MHz}\right)$ by changing drastically the electronic parameters from those of $\left[\mathrm{Gd}(\mathrm{DOTA})\left(\mathrm{H}_{2} \mathrm{O}\right)\right]^{-}$. As a crude visual fitting procedure, we set the trace of the square of the Zero Field Splitting 
operator $\Delta^{2}$ to $9 \cdot 10^{19} \mathrm{~s}^{-2}$. This leads to a much faster electron spin relaxation than what Powell et al. obtained for $\left[\mathrm{Gd}(\mathrm{DOTA})\left(\mathrm{H}_{2} \mathrm{O}\right)\right]^{-}$, thus significantly reducing the relaxivity. Preliminary X-band $(9.425 \mathrm{GHz})$ EPR measurements indicate that the electron spin relaxation of

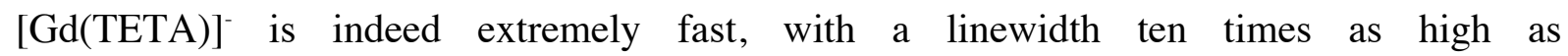
$\left[\mathrm{Gd}(\mathrm{DOTA})\left(\mathrm{H}_{2} \mathrm{O}\right)\right]^{-}$(Figure 14$)$. We see that in this respect [Gd(TETA)]- is definitely not the good model of the outer-sphere relaxivity of $\left[\mathrm{Gd}(\mathrm{DOTA})\left(\mathrm{H}_{2} \mathrm{O}\right)\right]^{-}$it is sometimes said to be. ${ }^{[2]}$ Incidentally, the $[\mathrm{Gd}(\mathrm{TETA})]^{-}$EPR spectrum displays more features than $\left[\mathrm{Gd}(\mathrm{DOTA})\left(\mathrm{H}_{2} \mathrm{O}\right]^{-}\right.$. For example the variable temperature measurements suggest the presence of several species with temperature-dependent proportions. A more complete analysis of the properties of this compound would be quite useful but is beyond the scope of this work.

The NMRD profile we calculate for $[\mathrm{Gd}(\mathrm{DOTP})]^{5-}$ is only $6 \%$ too low (6.8 instead of 7.2 $\mathrm{mM}^{-1} \mathrm{~s}^{-1}$ at $\left.0.01 \mathrm{MHz}\right)$ when using the $\left[\mathrm{Gd}(\mathrm{DOTA})\left(\mathrm{H}_{2} \mathrm{O}\right)\right]^{-}$parameters. Aime et al.[46] obtained a good fit of their NMRD data using two contributions: Freed's force-free model with $a_{G d H}=3.76 \AA\left(r_{l o s}=3.3 \mathrm{~s}^{-1} \mathrm{mM}^{-1}\right.$ at $\left.0.1 \mathrm{MHz}\right)$, and an inner-sphere-like contribution with hydration number $q=1$ and a residence time of 3000 ps. Our results indicate that such a long correlation time is not necessary, as our second-shell data (with a much shorter residence time of $56 \mathrm{ps}$ ) is already able to account for the major part of the observed relaxivity. The low field part of the profile is correctly reproduced after a slight adjustment of the electron spin parameters (results of the fitting procedure are reported in Table 9). However the agreement is not perfect at higher fields. This might be because the model of relaxation through diffusion is not adequate for this complex. Indeed the residence time we observe in the second shell of $[\mathrm{Gd}(\mathrm{DOTP})]^{5-}(56 \mathrm{ps})$ is not negligible with respect to the usual rotational correlation time of such complexes (60-80 ps $\left.^{[27]}\right)$. Thus a purely translational diffusive motion (as described by Smoluchowski's equation) might not be strictly valid in this case. 
In the case of the macrocyclic complexes, the partial rdf for the hydrophilic and hydrophobic regions (Figure 4) enables us to estimate their respective contributions to the outer-sphere relaxivity. Depending on the complex, the hydrophilic contribution increases from $63 \%$ of the overall low-field outer-sphere relaxivity for [Gd(TETA) $]^{-}$to $71 \%$ for $\left[\mathrm{Gd}(\mathrm{DOTA})\left(\mathrm{H}_{2} \mathrm{O}\right)\right]^{-}$and $73 \%$ for $[\operatorname{Gd}(\mathrm{DOTP})]^{5-}$.

\section{Conclusion}

We have been conducting an investigation of the outer-sphere hydration of polyaminocarboxylate and polyaminophosphonate gadolinium chelates. So far a force-free model had been assumed in the analysis of magnetic resonance experiments. We have found that a more realistic description is necessary for a better understanding of the nuclear relaxation properties of aqueous solutions of these compounds.

Beyond the structural differences of the studied complexes we find similarities that can be extended to other compounds of the same class. A few water molecules bind through hydrogen bounds to the hydrophilic groups of the ligand (their exact number depending on the number of such residues available for binding) forming a second coordination shell. The behavior of this second shell is therefore highly dependent on the charge distribution of the Gd(III) chelate. Depending on the ligand the structure can be highly anisotropic as was found for the complexes of the macrocyclic ligands TETA $^{4-}$, DOTA ${ }^{4-}$ and DOTP ${ }^{8-}$. These water molecules have a very short lifetime in this second shell compared to the inner sphere, typically 20 to 25 ps for polyaminocarboxylate complexes (versus microseconds for an innersphere water molecule). The water molecules surrounding the hydrophobic part of the complexes are randomly oriented and their lifetime approaches that of water for self-diffusion in neat water $\left(3 \mathrm{ps}^{[10]}\right)$. As can be seen from the example of $[\operatorname{Gd}(\mathrm{DOTP})]^{5-}$, the use of different ligand types (such as polyaminophosphonates) can increase the outer-sphere 
relaxivity by stabilizing the second coordination shell. Furthermore, due to the anisotropy of this hydration shell, the hydrophilic side of the complex can be the source of as much as $73 \%$ of the outer-sphere relaxivity at low field.

We have shown the limitations of Freed's force-free model for some complexes, notably $[\mathrm{Gd}(\mathrm{DOTP})]^{5-}$. We can relate our results to experimental data through a numerical approach related to Freed's model including electron spin relaxation. Using a method based on finite differences, one can calculate spectral density functions from the readily available radial distribution function $g(r)$. Our results are in general agreement with the experimental data without needing to introduce too many adjustable parameters. However, a quantitative agreement in all cases will only be possible when the pending questions regarding the electron spin relaxation are settled.

\section{Acknowledgement}

We wish to thank Dr. T. Kowall (University of Lausanne) and Dr. O. Schafer (Institute of Inorganic Chemistry, University of Fribourg, Fribourg, Switzerland) for their initial help. We are appreciative of the Swiss National Science Foundation and the Office for Education and Science (OFES) for their financial support. This research was carried out in the frame of the EC D18 Action "Lanthanide Chemistry for Diagnosis and Therapy".

\section{References}

[1] R. B. Lauffer, Chem. Rev. 1987, 87, 901-927.

[2] P. Caravan, J. J. Ellison, T. J. McMurry, R. B. Lauffer, Chem. Rev. 1999, 99, 22932352

[3] J. H. Freed, J. Chem. Phys. 1978, 68, 4034-4037.

[4] L.-P. Hwang, J. H. Freed, J. Chem. Phys. 1975, 63, 4017-4025. 
[5] J. W. Chen, R. L. Belford, R. B. Clarkson, J. Phys. Chem. A 1998, 102, 2117-2130.

[6] M. Botta, Eur. J. Inorg. Chem. 2000, 399-407.

[7] T. Kowall, F. Foglia, L. Helm, A. E. Merbach, J. Am. Chem. Soc. 1995, 117, 37903799.

[8] T. Kowall, F. Foglia, L. Helm, A. E. Merbach, J. Phys. Chem. 1995, 99, 13078-13087.

[9] T. Kowall, F. Foglia, L. Helm, A. E. Merbach, Chem. Eur. J. 1996, 2, 285-294.

[10] A. Bleuzen, F. Foglia, E. Furet, L. Helm, A. E. Merbach, J. Weber, J. Am. Chem. Soc. 1996, $118,12777-12787$.

[11] R. Fossheim, S. G. Dahl, Acta Chim. Scand. 1990, 44, 698-706.

[12] R. Fossheim, H. Dugstad, S. G. Dahl, J. Med. Chem. 1991, 34, 819-826.

[13] D. E. Reichert, R. D. Hancock, M. J. Welch, Inorg. Chem. 1996, 35, 7013-7020.

[14] U. Cosentino, G. Moro, D. Pitea, A. Villa, P. C. Fantucci, A. Maiocchi, F. Uggeri, J. Phys. Chem. A 1998, 102, 4606-4614.

[15] E. S. Henriques, M. Bastos, C. F. G. C. Geraldes, M. J. Ramos, Int. J. Quant. Chem. 1999, 73, 237-248.

[16] O. Schafer, C. Daul, Int. J. Quant. Chem. 1997, 61, 541-546.

[17] B. H. Besler, K. M. J. Merz, P. A. Kollman, J. Comp. Chem. 1990, 11, 431-439.

[18] M. J. Frisch, G. W. Trucks, H. B. Schlegel, P. M. W. Gill, B. G. Johnson, M. A. Robb, J. R. Cheeseman, T. A. Keith, G. A. Petersson, J. A. Montgomery, K. Raghavachari, M. A. Al-Laham, V. G. Zakrewski, J. V. Ortiz, J. B. Foresman, J. Cioslowski, B. B. Stefanov, A. Nanayakkara, M. Challacombe, C. Y. Peng, A. P. Y., W. Chen, M. W. Wong, J. L. Andres, E. S. Replogle, R. Gomperts, R. L. Martin, D. J. Fox, J. S. Binkley, D. J. Defrees, J. Baker, J. P. Stewart, M. Head-Gordon, C. Gonzalez, J. A. Pople, Gaussian 94, Gaussian Inc., Pittsburgh, 1995. 
[19] M.-R. Spirlet, J. Rebizant, M.-F. Loncin, J. F. Desreux, Inorg. Chem. 1984, 23, 42784283

[20] C. A. Chang, L. C. Francesconi, M. F. Malley, K. Kumar, J. Z. Gougoutas, M. F. Tweedle, Inorg. Chem. 1993, 32, 3501-3508.

[21] T.-Z. Jin, S.-F. Zhao, G.-X. Xu, Y.-Z. Han, N.-C. Shi, Z.-S. Ma, H. Xuebao, Acta Chim. Sinica 1991, 49, 569.

[22] G. Jamieson, private communication, Nycomed-Salutar, Inc. 1990.

[23] M. Dolg, H. Stoll, A. Savin, H. Preuss, Theor. Chim. Acta 1989, 75, 173-194.

[24] E. J. Baerends, Amsterdam Density Functional (ADF), Scientific Computing and Modelling, Amsterdam, 1997.

[25] A. D. Becke, J. Chem. Phys. 1986, 85, 7184-7187.

[26] J. Perdew, Phys. Rev. B 1986, 33, 8822-8824.

[27] D. H. Powell, O. M. Ni Dubhghaill, D. Pubanz, L. Helm, Y. S. Lebedev, W. Schlaepfer, A. E. Merbach, J. Am. Chem. Soc. 1996, 118, 9333-9346.

[28] S. Aime, M. Botta, M. Fasano, M. P. M. Marques, C. F. G. C. Geraldes, D. Pubanz, A. E. Merbach, Inorg. Chem. 1997, 36, 2059-2068.

[29] W. L. Jorgensen, J. Chandrasekhar, J. D. Madura, R. W. Impey, M. L. Klein, J. Chem. Phys. 1983, 79, 926-935.

[30] W. F. van Gunsteren, H. J. C. Berendsen, GROMOS86, Biomolecular Software, Groningen, 1986.

[31] J.-P. Ryckaert, G. Ciccoti, H. J. C. Berendsen, J. Comput. Phys. 1977, 23, 327-341.

[32] H. J. C. Berendsen, J. P. M. Postma, v. G. W. F., A. DiNola, J. R. Haak, J. Chem. Phys. 1984, 81, 3684-3690.

[33] R. W. Impey, P. A. Madden, I. R. McDonald, J. Phys. Chem. 1983, 87, 5071-5083.

[34] A. Luzar, D. Chandler, J. Chem. Phys. 1993, 98, 8160-8173. 
[35] S. G. Kalko, E. Guàrdia, J. A. Padró, J. Phys. Chem. B 1999, 103, 3935-3941.

[36] M. Sunnerhagen, V. P. Denisov, K. Venu, A. M. J. J. Bonvin, J. Carey, B. Halle, G. Otting, J. Mol. Biol. 1998, 282, 847-858.

[37] A. M. J. J. Bonvin, M. Sunnerhagen, G. Otting, W. F. van Gunsteren, J. Mol. Biol. 1998, 282, 859-873.

[38] M. Ferrario, M. Haughney, I. R. McDonald, M. L. Klein, J. Chem. Phys. 1990, 93, $5156-5166$.

[39] A. Abragam, The Principles of Nuclear Magnetism, Clarendon Press, Oxford, 1961.

[40] R. Mills, J. Phys. Chem. 1973, 77, 685-688.

[41] D. H. Powell, A. E. Merbach, G. Gonzalez, E. Brücher, K. Micskei, M. F. Ottaviani, K. Köhler, A. von Zelewsky, O. Y. Grinberg, Y. S. Lebedev, Helv. Chim. Acta 1993, $76,2129-2146$.

[42] T. I. Smirnova, A. I. Smirnov, R. L. Belford, R. B. Clarkson, J. Am. Chem. Soc. 1998, $120,5060-5072$.

[43] E. Strandberg, P.-O. Westlund, J.Mag. Res. A 1996, 122, 179-191.

[44] S. Rast, P. H. Fries, E. Belorizky, J. Chim. Phys. 1999, 96, 1543-1550.

[45] A. Borel, É. Tóth, L. Helm, A. Jánossy, A. E. Merbach, Phys. Chem. Chem. Phys. 2000, 2, 1311-1318.

[46] S. Aime, M. Botta, E. Terreno, P. L. Anelli, F. Uggeri, Mag. Res. Med. 1993, 30, 583591. 


\section{Legends}

Figure 1. Ligands used in the studied complexes.

Figure 2. Rdf for water (a) oxygen and (b) hydrogen around Gd of [Gd(TETA)] $(-$ ), $\left[\operatorname{Gd}(\text { DOTA })\left(\mathrm{H}_{2} \mathrm{O}\right)\right]^{-}(\ldots .$.$) and [\mathrm{Gd}(\mathrm{DOTP})]^{5-}$

( --- )

Figure 3. (a) Model of [Gd(TETA)], and division of the surrounding space into hydrophilic (up) and hydrophobic (down) hemispheres. (b) Electrostatic potential in atomic units at the molecular surface of [Gd(TETA)] in the hydrophilic (carboxylates, left) and hydrophobic (macrocycle, right) regions

Figure 4. Partial rdf of water oxygens in the (a) hydrophilic and (b) hydrophobic hemispheres of $[\operatorname{Gd}(T E T A)]^{-}(-),\left[\operatorname{Gd}(\operatorname{DOTA})\left(\mathrm{H}_{2} \mathrm{O}\right)\right]^{-}(\ldots .$.$) and [\operatorname{Gd}(\operatorname{DOTP})]^{5-}(-.--)$

Figure 5. Rdf around (a) carboxylate oxygens and (b) nitrogens of [Gd(TETA)]'. A distinction is made between oxygen atoms bound to the metal ion $\left(\mathrm{O}_{c}\right)$ and free $\left(\mathrm{O}_{\mathrm{f}}\right)$.

Figure 6. Orientation angle $\Theta$ definition and limiting values of $\cos \Theta$

Figure 7. Average $\cos \Theta$ as a function of the metal-oxygen distance for [Gd(TETA)]: Dotted lines have the standard deviation added/subtracted.

Figure 8. Average $\cos \Theta$ as a function of the metal-oxygen distance for [Gd(TETA)] ${ }^{-}$),$\left[\operatorname{Gd}(\operatorname{DOTA})\left(\mathrm{H}_{2} \mathrm{O}\right)\right]^{-}(\ldots .$.$) and [\operatorname{Gd}(\mathrm{DOTP})]^{5-}(----)$

Figure 9. Rdf for water (a) oxygens and (b) hydrogens around Gd of $\left[\operatorname{Gd}(\mathrm{DTPA})\left(\mathrm{H}_{2} \mathrm{O}\right)\right]^{2-}$ $(-)$ and [Gd(DTPA-BMA $\left.)\left(\mathrm{H}_{2} \mathrm{O}\right)\right](----)$.

Figure 10. Water oxygens rdf around inner-sphere water hydrogens of $\left[\operatorname{Gd}(D T P A)\left(\mathrm{H}_{2} \mathrm{O}\right)\right]^{2-}(---),\left[\operatorname{Gd}(\operatorname{DTPA}-\mathrm{BMA})\left(\mathrm{H}_{2} \mathrm{O}\right)\right](\ldots \ldots)$ and $\left[\operatorname{Gd}(\operatorname{DOTA})\left(\mathrm{H}_{2} \mathrm{O}\right)\right]^{-}(-)$.

Figure 11. Criteria for hydrogen bonding between inner-sphere and outer-sphere water.

Figure 12. Outer-sphere relaxivity profile of (a) $\left[\mathrm{Gd}(\mathrm{DOTA})\left(\mathrm{H}_{2} \mathrm{O}\right)\right]^{-}$, (b) $[\mathrm{Gd}(\mathrm{DTPA}$ BMA $\left.)\left(\mathrm{H}_{2} \mathrm{O}\right)\right]$ and $(\mathrm{c})\left[\mathrm{Gd}(\mathrm{DTPA})\left(\mathrm{H}_{2} \mathrm{O}\right)\right]^{2-}$ from MD simulations $(-)$, from Freed's forcefree model (----), and with $a_{G d H}=3.0 \AA(\ldots .$. 
Figure 13. NMRD profile of (a) [Gd(TETA)] ${ }^{-}$and

(b) $[\mathrm{Gd}(\mathrm{DOTP})]^{5-}$. The dotted lines use the electron relaxation parameters determined by Powell et al. for [Gd(DOTA $\left.)\left(\mathrm{H}_{2} \mathrm{O}\right)\right]^{-}$.

Figure 14. Room-temperature X-band EPR spectra of [Gd(TETA)] and $\left[\operatorname{Gd}(\operatorname{DOTA})\left(\mathrm{H}_{2} \mathrm{O}\right)\right]^{-}$. 


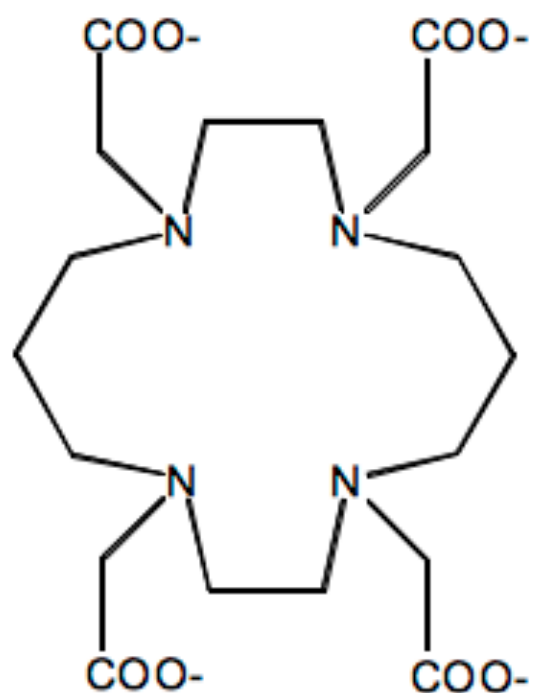

TETA ${ }^{4-}$

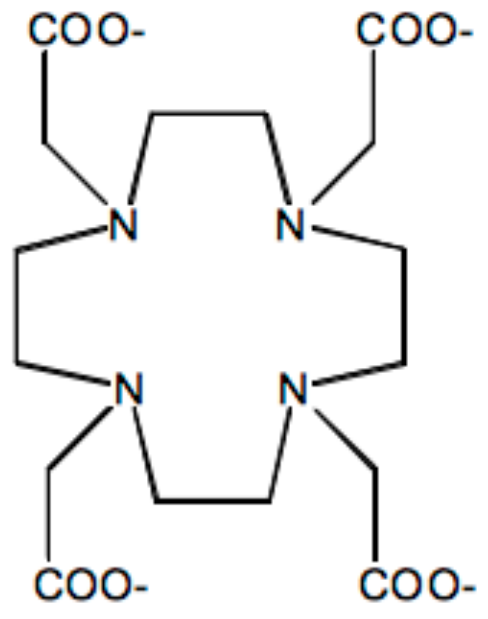

DOTA ${ }^{4-}$
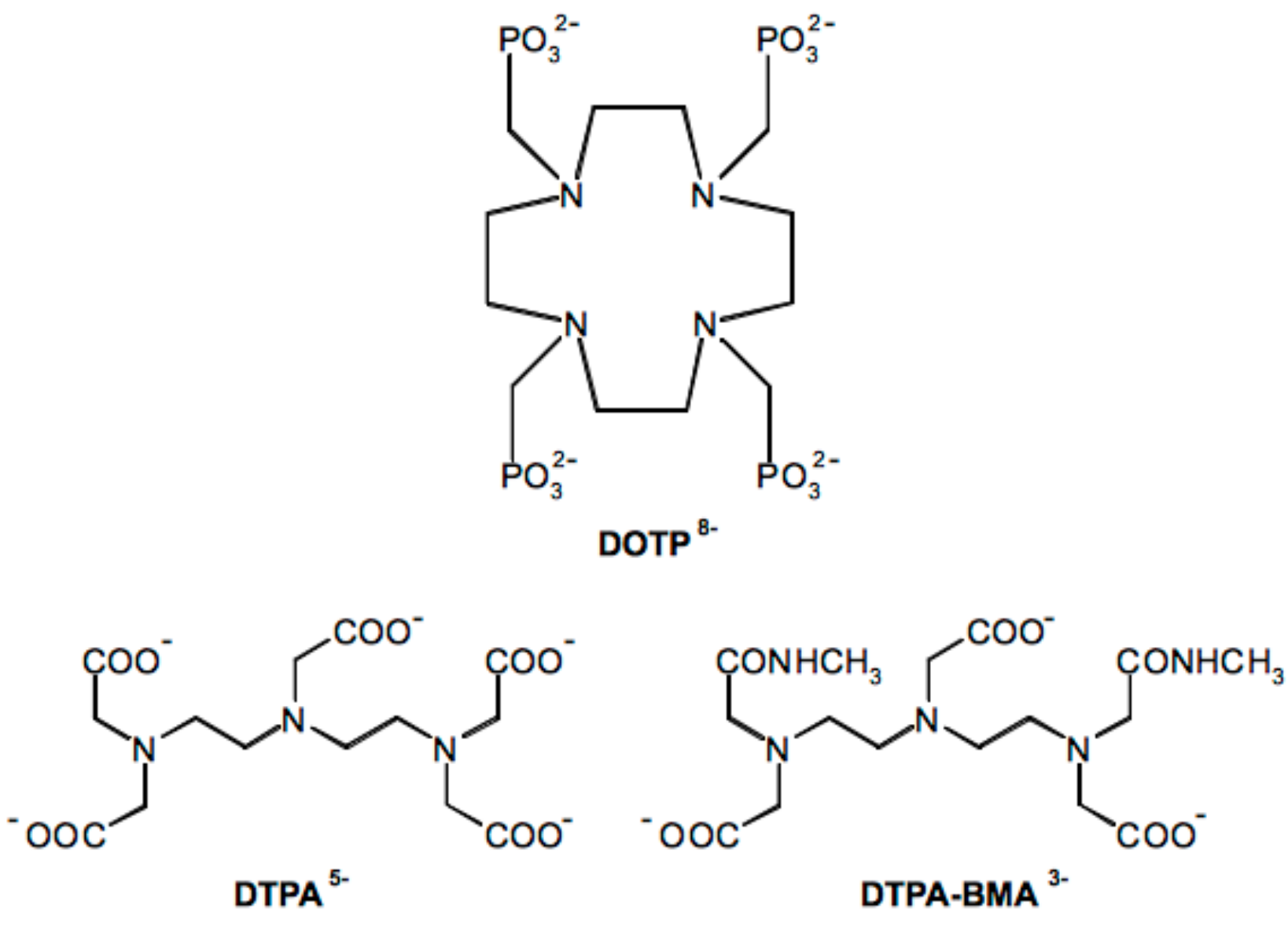

Fig. 1 

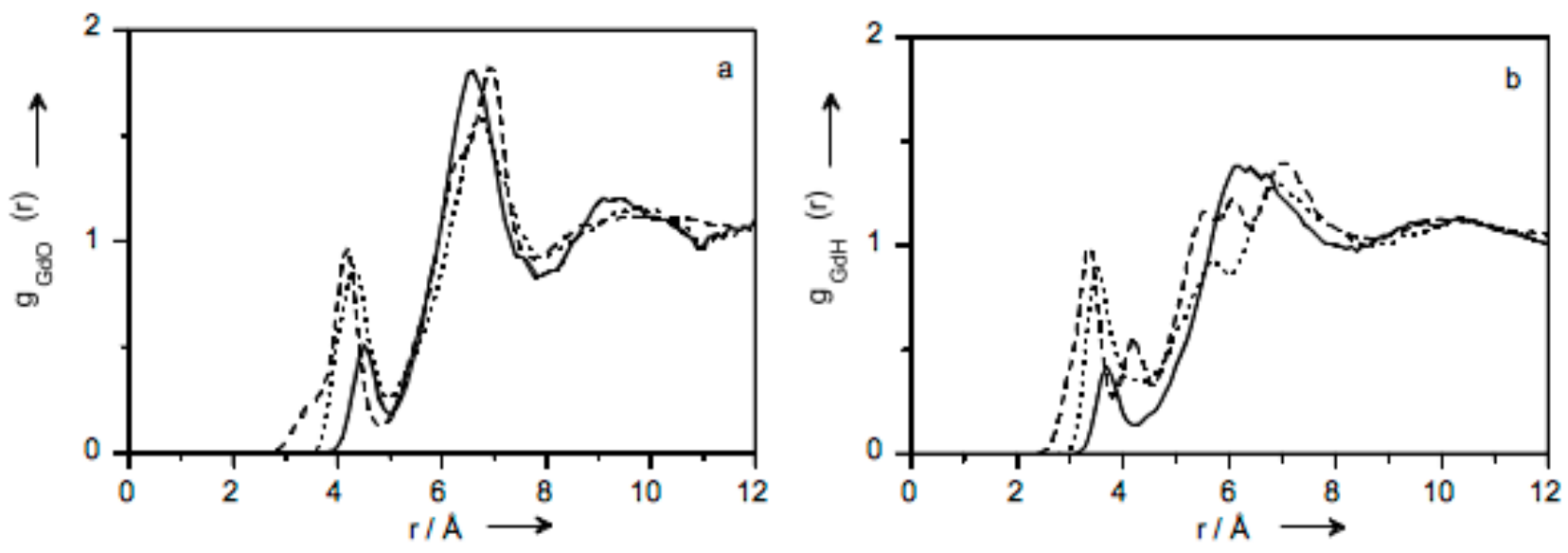

Fig. 2 

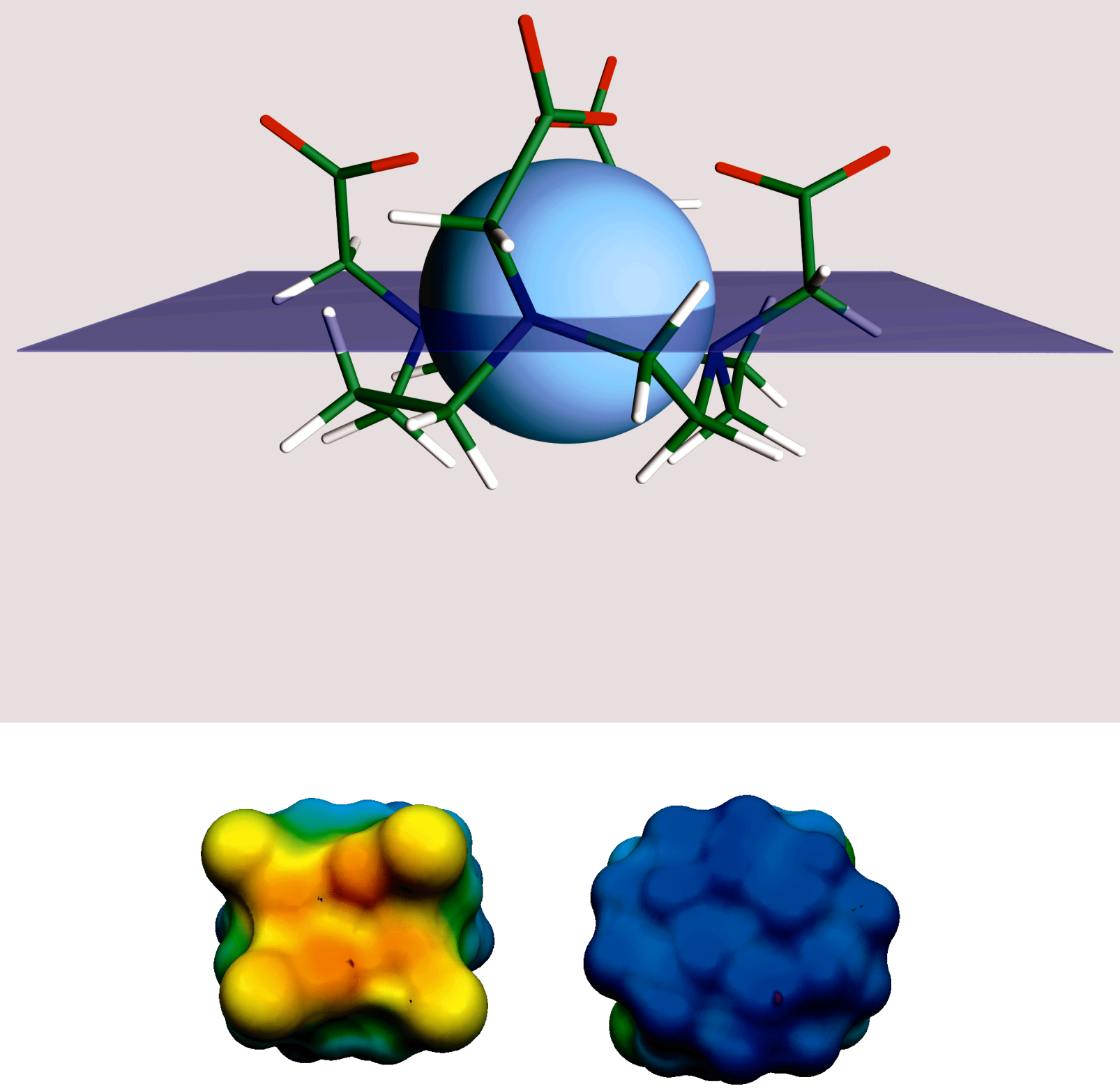

$-0.4$

Fig. 3 


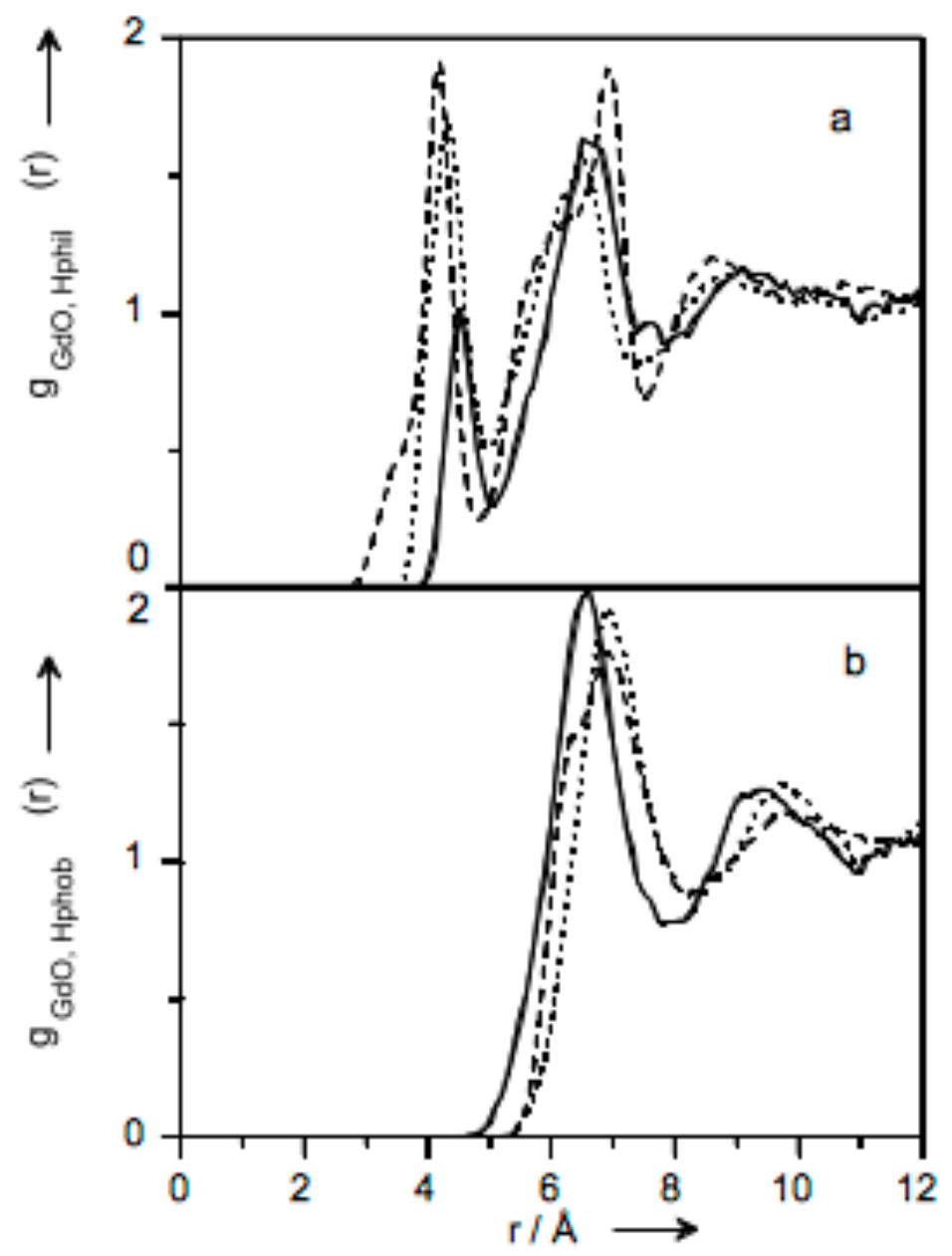

Fig. 4 

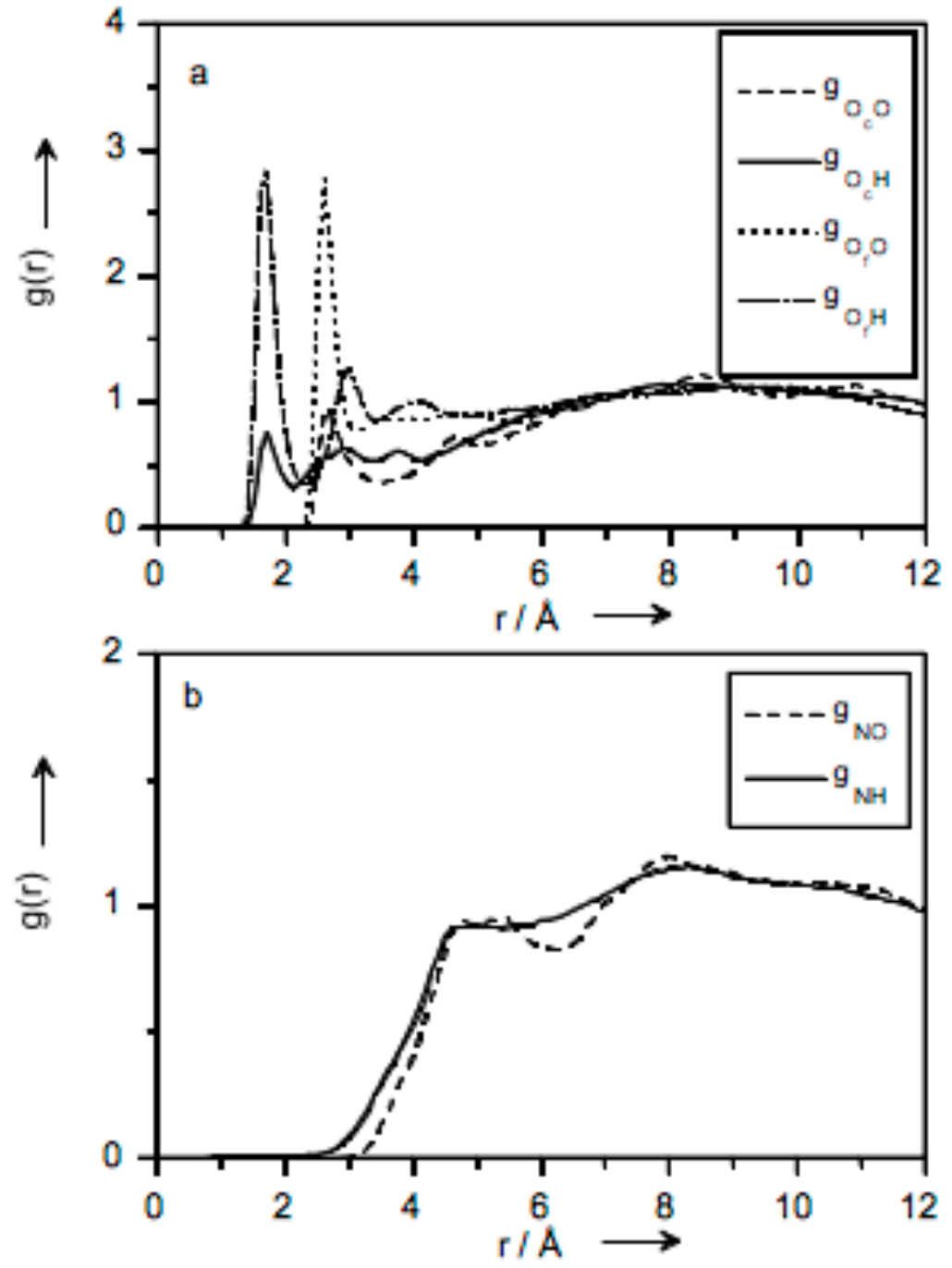

Fig. 5 

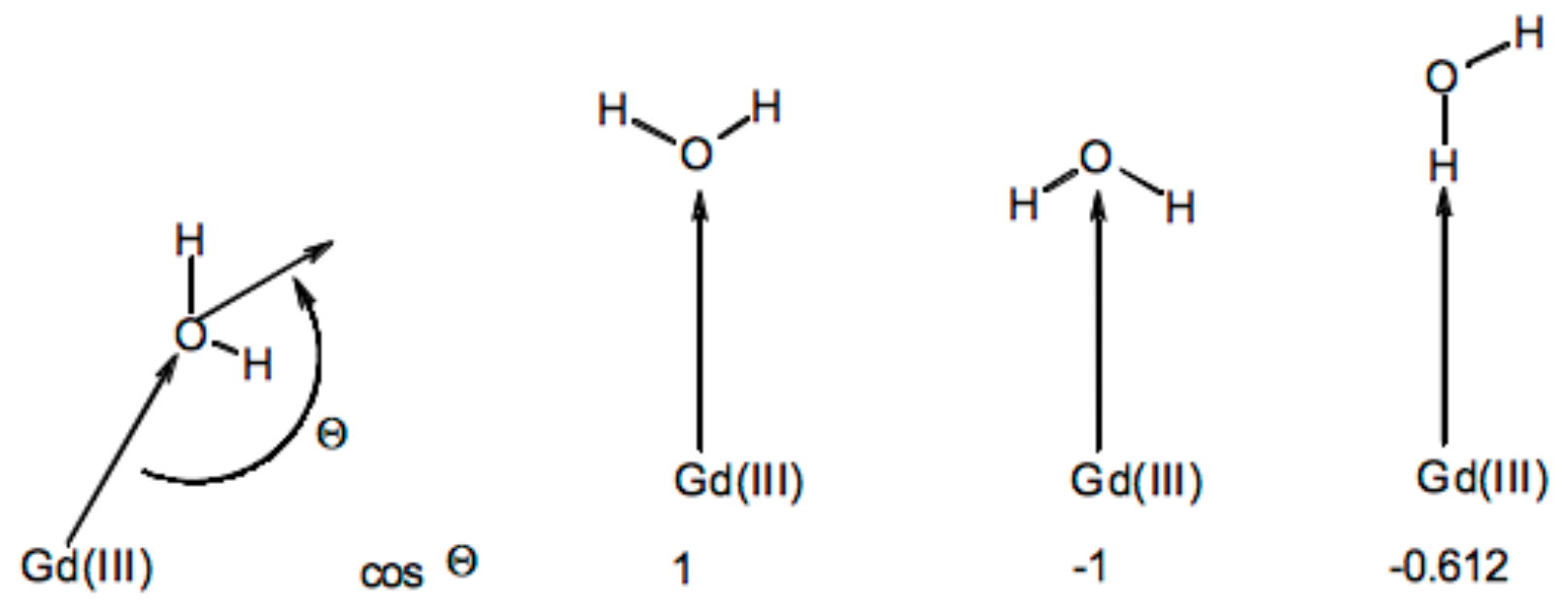

Fig. 6 


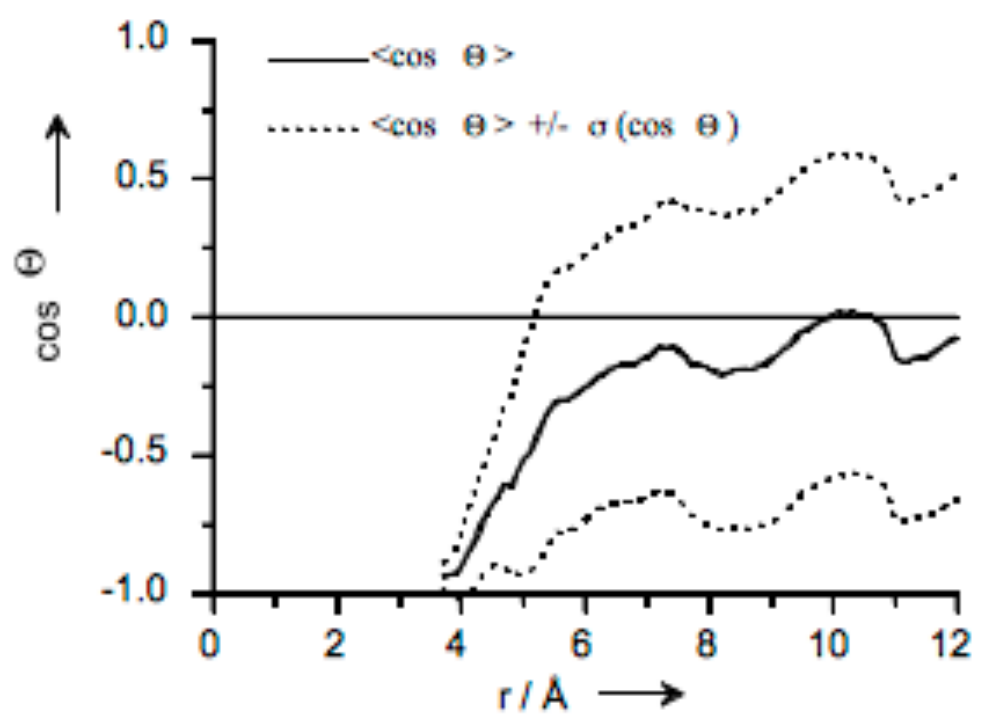

Fig. 7 


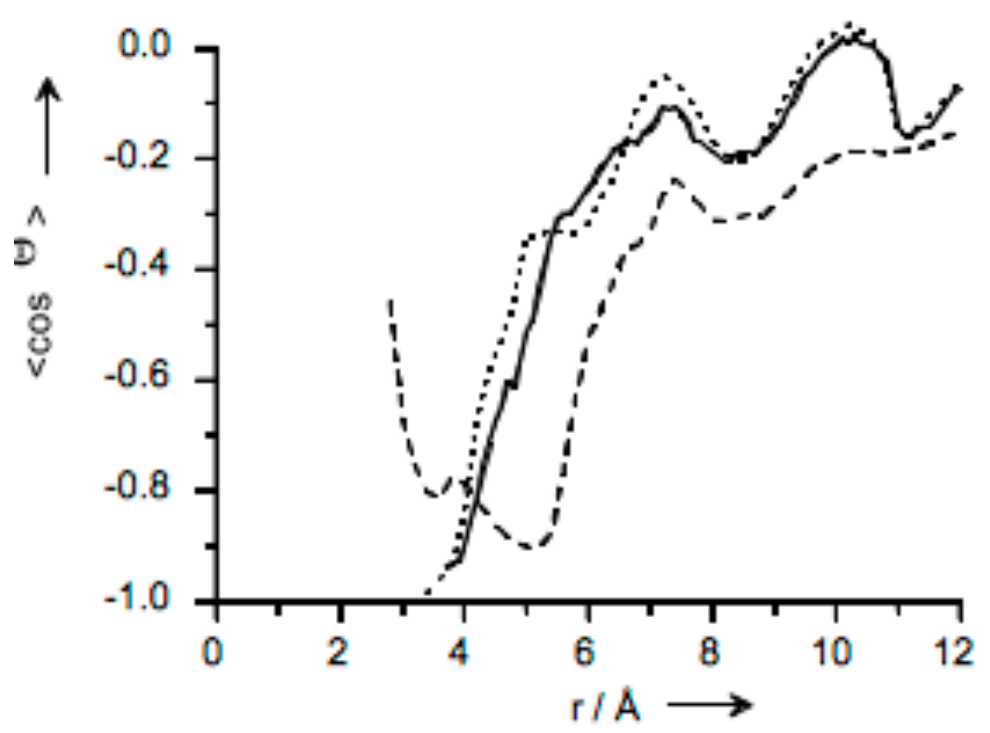

Fig. 8 

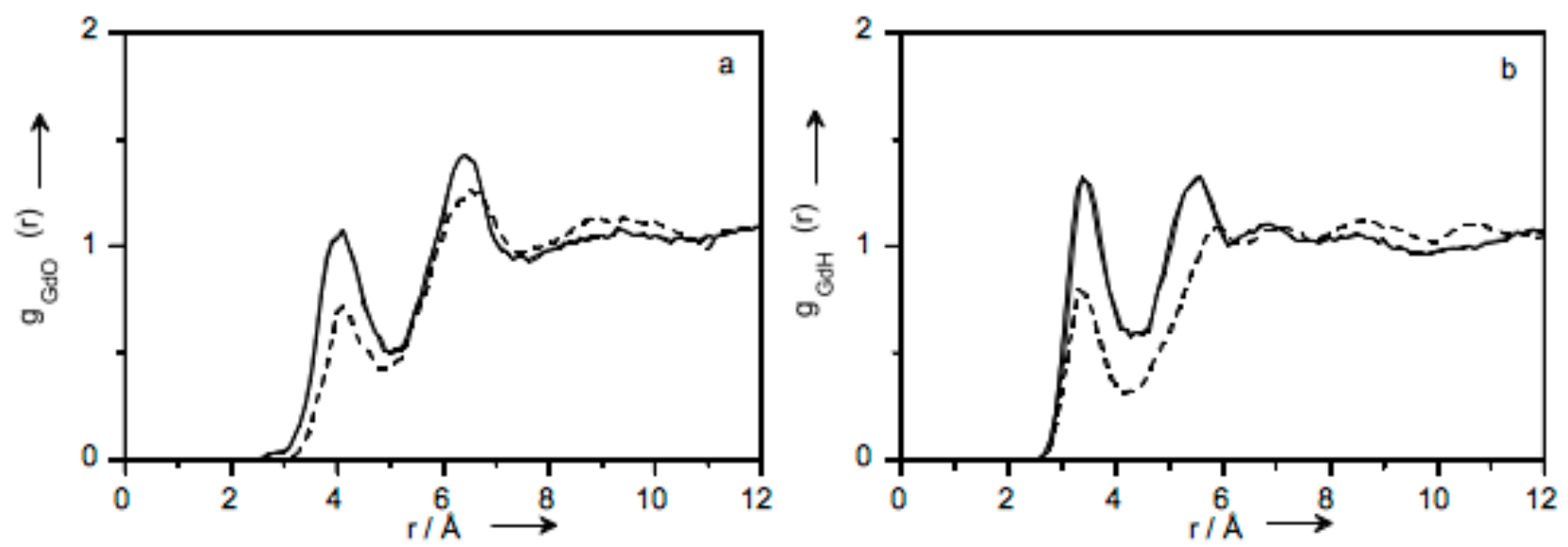

Fig. 9 


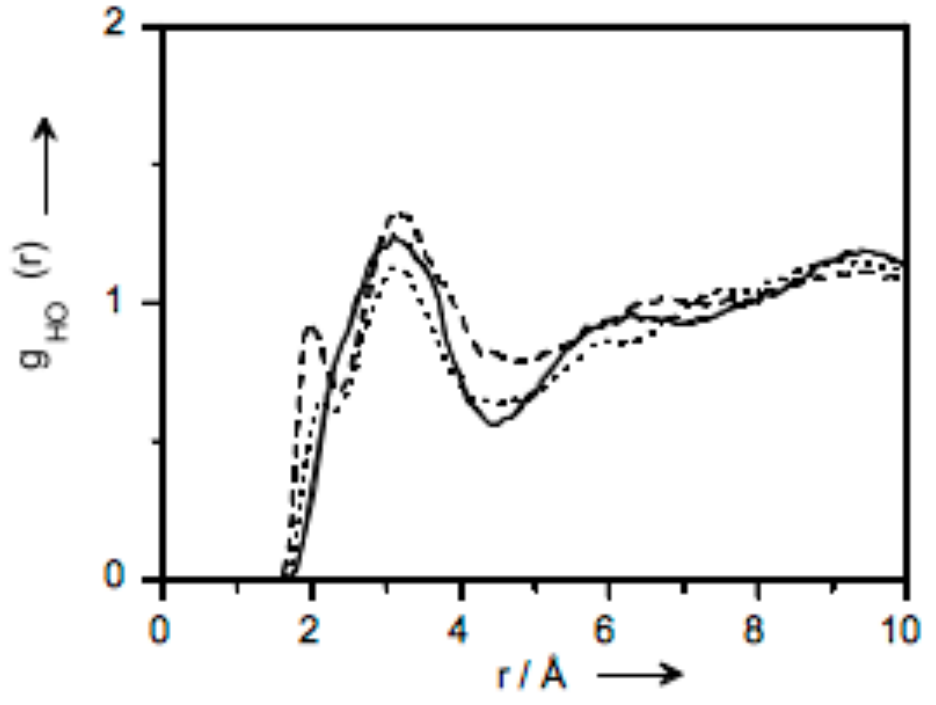

Fig. 10 


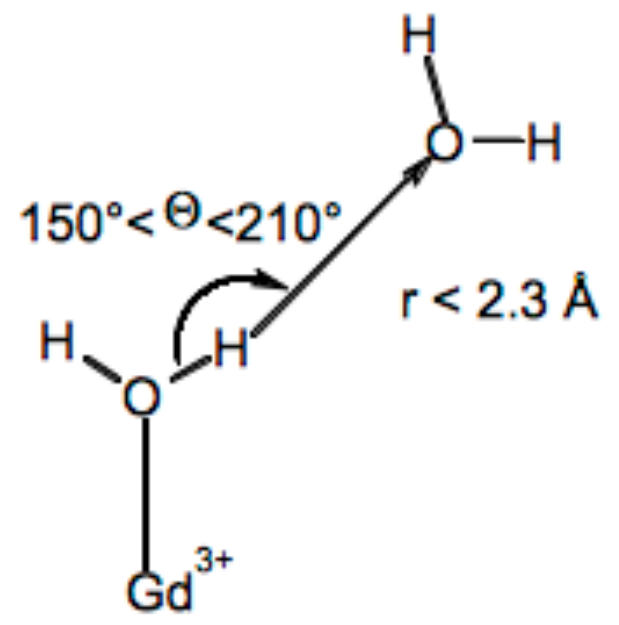

Fig. 11 

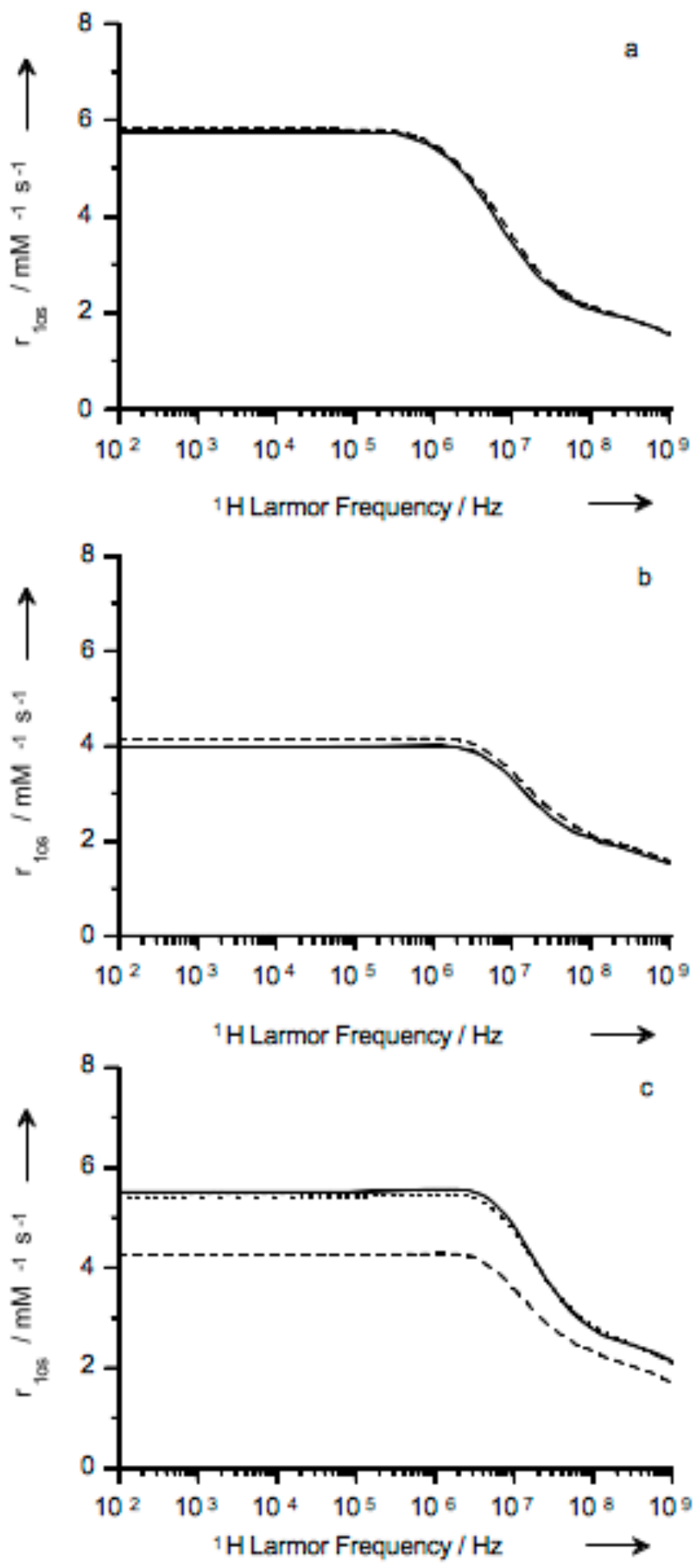

Fig. 12 

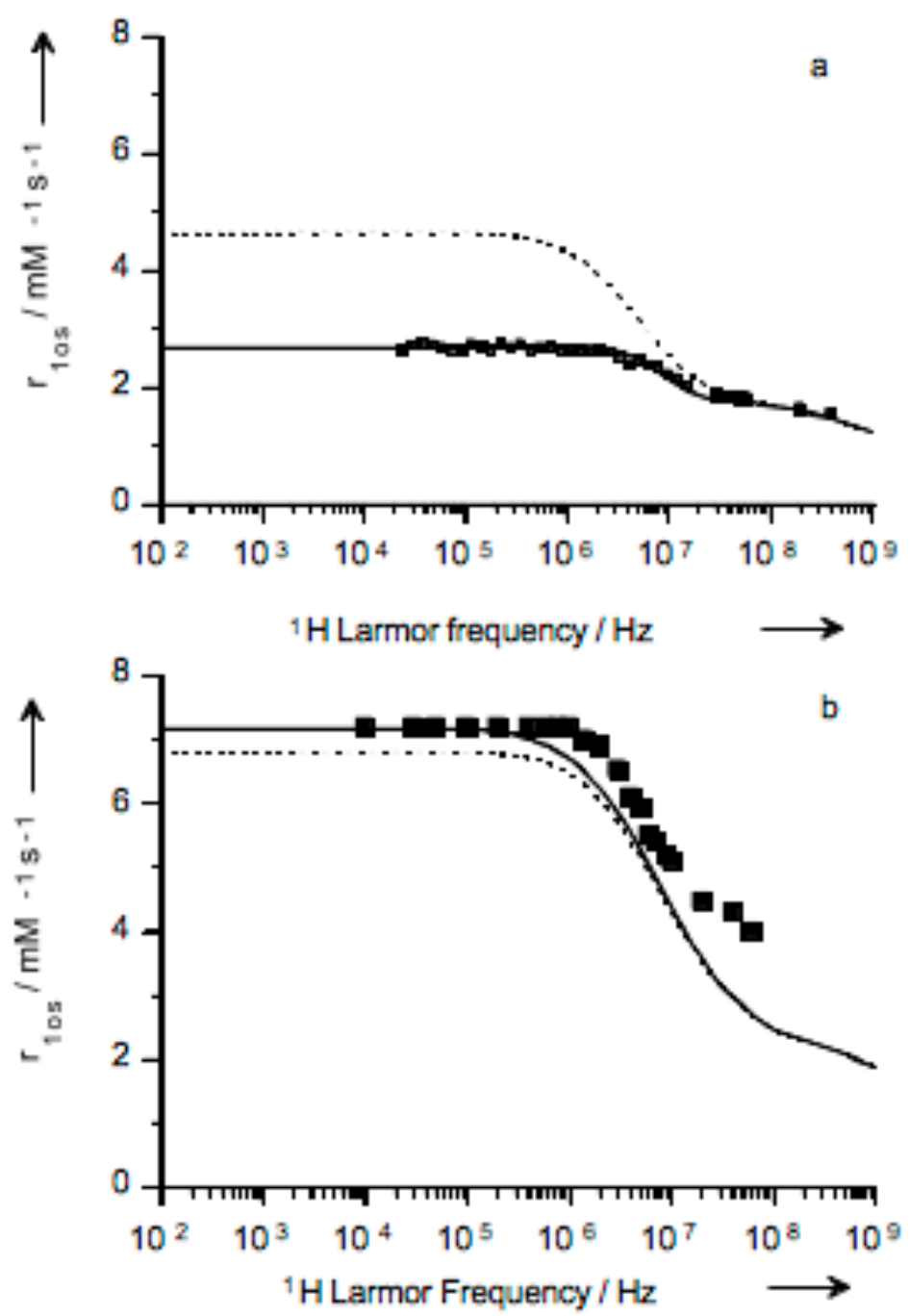

Fig. 13 


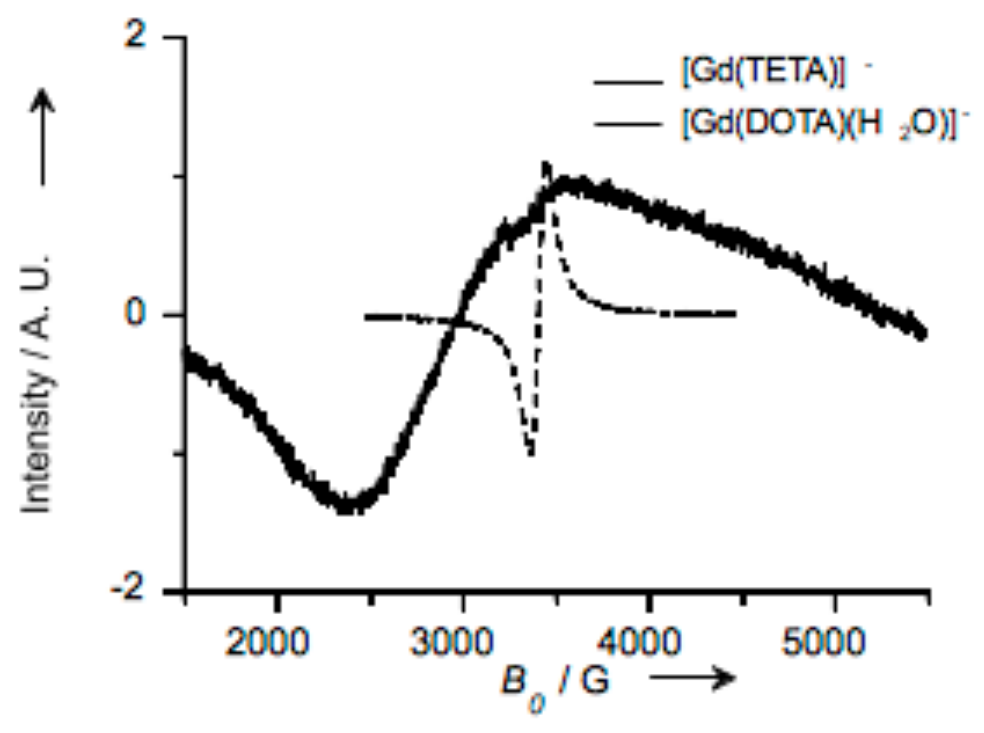

Fig. 14 


\section{Tables}

Table 1. Atomic charges derived from ab initio calculations for $\left[\mathrm{Gd}\left(\mathrm{L}^{-n}\right)\left(\mathrm{H}_{2} \mathrm{O}\right)_{\mathrm{x}}\right]^{3-\mathrm{n}}$

\begin{tabular}{|c|c|c|c|c|c|}
\hline & {$[\text { Gd(TETA) }]^{-}$} & {$\left[\mathrm{Gd}(\mathrm{DOTA})\left(\mathrm{H}_{2} \mathrm{O}\right)\right]^{-}$} & {$[\mathrm{Gd}(\mathrm{DOTP})]^{5-}$} & {$\left[\mathrm{Gd}(\mathrm{DTPA})\left(\mathrm{H}_{2} \mathrm{O}\right)\right]^{2-}$} & [Gd(DTPA-BMA $\left.)\left(\mathrm{H}_{2} \mathrm{O}\right)\right]$ \\
\hline Gd & 2.17 & 2.12 & 2.35 & 2.30 & 1.96 \\
\hline $\mathrm{N}$ amine & -0.10 & -0.81 & -0.25 & 0.20 & $0.00^{[\mathrm{a}]} / 0.60$ \\
\hline C ethylene bridge & -0.15 & -0.042 & -0.18 & 0.00 & $0.00^{[\mathrm{a}]} /-0.20^{[\mathrm{b}]}$ \\
\hline H ethylene bridge & 0.09 & 0.13 & 0.14 & 0.03 & 0.10 \\
\hline C methyl / methylene & -0.55 & 0.02 & -0.50 & -0.50 & -0.20 \\
\hline H methylene & 0.20 & 0.14 & 0.14 & 0.03 & 0.13 \\
\hline $\mathrm{C}$ carboxylate / $\mathrm{P}$ & 1.00 & 0.81 & 1.40 & 0.90 & 0.90 \\
\hline $\begin{array}{l}\mathrm{O}_{\mathrm{c}} \text { carboxylate / phosphonate } \\
\text { (coordinating) }\end{array}$ & -0.85 & -0.81 & -1.00 & -0.90 & $-0.65^{[\mathrm{c}]} /-0.80^{[\mathrm{d}]}$ \\
\hline $\mathrm{O}_{\mathrm{f}}$ carboxylate / phosphonate (free) & -0.75 & -0.71 & -0.98 & -0.80 & -0.70 \\
\hline O inner-sphere water & - & -0.60 & - & -1.00 & -0.80 \\
\hline $\mathrm{H}$ inner-sphere water & - & 0.30 & - & 0.50 & 0.40 \\
\hline $\mathrm{N}$ amide & - & - & - & - & -0.45 \\
\hline $\mathrm{O}$ amide & - & - & - & - & -0.65 \\
\hline $\mathrm{H}$ amide & - & - & - & - & 0.35 \\
\hline C N-methyl & - & - & - & - & -0.25 \\
\hline
\end{tabular}
${ }^{[a]}$ : central
[b]: terminal
${ }^{[c]}$ : amide group
[d]. carboxylate group 
Table 2. Selected distances from the DFT-optimized structure of [Gd(DOTP) $]^{5-}$

\begin{tabular}{cc}
\hline Distances & $\AA$ \\
Gd-O & $2.390 \pm 0.018 \AA$ \\
Gd-N & $3.041 \pm 0.055 \AA$ \\
$\mathrm{C}-\mathrm{P}$ & $1.908 \pm 0.007 \AA$ \\
$\mathrm{P}-\mathrm{O}$ & $1.577 \pm 0.018 \AA$ \\
\hline
\end{tabular}


Table 3. Overview of simulation parameters for $\left[\mathrm{Gd}\left(\mathrm{L}^{-n}\right)\left(\mathrm{H}_{2} \mathrm{O}\right)_{\mathrm{x}}\right]^{3-\mathrm{n}}$

\begin{tabular}{|c|c|c|c|c|c|}
\hline & {$[\text { Gd(TETA) }]^{-}$} & {$\left[\mathrm{Gd}(\mathrm{DOTA})\left(\mathrm{H}_{2} \mathrm{O}\right)\right]^{-}$} & {$[\mathrm{Gd}(\mathrm{DOTP})]^{5-}$} & {$\left[\mathrm{Gd}(\mathrm{DTPA})\left(\mathrm{H}_{2} \mathrm{O}\right)\right]^{2-}$} & {$\left[\mathrm{Gd}(\mathrm{DTPA}-\mathrm{BMA})\left(\mathrm{H}_{2} \mathrm{O}\right)\right]$} \\
\hline Number of water molecules & 500 & 490 & 1426 & 498 & 498 \\
\hline Equilibration time [ps] & 32 & 32 & 32 & 32 & 32 \\
\hline Simulation time $[\mathrm{ps}]$ & 262 & 262 & 524 & 262 & 262 \\
\hline Stored configurations & 4096 & 4096 & 8192 & 4096 & 4096 \\
\hline Cutoff radius $[\AA]$ & 11.0 & 11.0 & 16.0 & 10.5 & 11.0 \\
\hline$\tau_{\mathrm{T}}[\mathrm{ps}]^{[\mathrm{a}]}$ & 0.01 & 0.01 & 0.01 & 0.01 & 0.01 \\
\hline$\tau_{\mathrm{P}}[\mathrm{ps}]^{[\mathrm{a}]}$ & 0.05 & 0.05 & 0.05 & 0.05 & 0.05 \\
\hline Average density $\left[\mathrm{g} / \mathrm{cm}^{3}\right]$ & 1.0315 & 1.0227 & 1.0315 & 1.0200 & 1.0486 \\
\hline Temperature $[\mathrm{K}]$ & 285 & 285 & 285 & 285 & 285 \\
\hline Pressure [atm] & 1 & 1 & 1 & 1 & 1 \\
\hline
\end{tabular}

${ }^{[a]}$ : relaxation times for temperature and pressure in the algorithm of Berendsen. 
Table 4. Rdf peak parameters and corresponding coordination number $q$ for water oxygen and hydrogens

\begin{tabular}{|c|c|c|c|c|c|c|}
\hline Complex & $\begin{array}{c}\text { O peak } \\
\text { position } \\
{[\AA]}\end{array}$ & 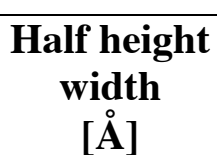 & $q_{o}$ & $\begin{array}{c}\text { H peak } \\
\text { position } \\
{[\AA]}\end{array}$ & $\begin{array}{l}\text { Half height } \\
\text { width } \\
\text { [̊]] }\end{array}$ & $q_{H}$ \\
\hline$[\text { [Gd(TETA)] }]^{-}$ & 4.5 & 0.5 & 2.5 & 3.7 & 0.5 & 2.6 \\
\hline$\left[\mathrm{Gd}(\mathrm{DOTA})\left(\mathrm{H}_{2} \mathrm{O}\right)\right]^{-}$ & 4.3 & 1.0 & 5.1 & 3.5 & 0.65 & 6.4 \\
\hline$[\operatorname{Gd}(\mathrm{DOTP})]^{5-}$ & 4.2 & 0.3 & 4.6 & 3.4 & 0.3 & 5.3 \\
\hline$\left[\operatorname{Gd}(\mathrm{DTPA})\left(\mathrm{H}_{2} \mathrm{O}\right)\right]^{2-}$ & 4.1 & 1.0 & 8.6 & 3.4 & 1.0 & 12.8 \\
\hline [Gd(DTPA-BMA $\left.)\left(\mathrm{H}_{2} \mathrm{O}\right)\right]$ & 4.1 & $(0.8)$ & 5.0 & 3.3 & $(0.5)$ & 7.0 \\
\hline
\end{tabular}


Table 5. Second-shell hydration parameters from coordination correlation function $\boldsymbol{n}(\boldsymbol{t})$

\begin{tabular}{|c|c|c|}
\hline Complex & Hydration number $q$ & Residence time $\tau_{M}[\mathrm{ps}]$ \\
\hline [Gd(TETA)] & 1.9 & 24.3 \\
\hline$\left[\mathrm{Gd}(\mathrm{DOTA})\left(\mathrm{H}_{2} \mathrm{O}\right)\right]^{-}$ & 4.3 & 27.4 \\
\hline$[\mathrm{Gd}(\mathrm{DOTP})]^{5-}$ & 4.3 & 56.1 \\
\hline$\left[\mathrm{Gd}(\mathrm{DTPA})\left(\mathrm{H}_{2} \mathrm{O}\right)\right]^{2-}$ & 6.9 & 20.3 \\
\hline [Gd(DTPA-BMA) $\left.\left(\mathrm{H}_{2} \mathrm{O}\right)\right]$ & 4.4 & 22.5 \\
\hline
\end{tabular}


Table 6. Hydrogen bond number and lifetime around coordinating $\left(O_{c}\right)$ and free $\left(O_{f}\right)$ carboxylate/phosphonate oxygens

\begin{tabular}{|c|c|c|c|c|}
\hline Complex & $q\left(O_{c}\right)$ & $\tau_{M}[\mathrm{ps}]$ & $q\left(O_{f}\right)$ & $\tau_{M}[\mathrm{ps}]$ \\
\hline [Gd(TETA) $]^{-}$ & 1.1 & 8.9 & 1.9 & 4.5 \\
\hline$\left[\operatorname{Gd}(\operatorname{DOTA})\left(\mathrm{H}_{2} \mathrm{O}\right)\right]^{-}$ & 1.0 & 14.7 & 2.3 & 6.8 \\
\hline$[\operatorname{Gd}(\mathrm{DOTP})]^{5-}$ & 1.6 & 27.8 & 2.7 & 27.7 \\
\hline$\left[\mathrm{Gd}(\mathrm{DTPA})\left(\mathrm{H}_{2} \mathrm{O}\right)\right]^{2-}$ & 1.1 & 9.0 & 2.6 & 7.8 \\
\hline [Gd(DTPA-BMA $\left.)\left(\mathrm{H}_{2} \mathrm{O}\right)\right]$ & 0.7 & 13.9 & 2.1 & 6.1 \\
\hline
\end{tabular}


Table 7. Probability for water molecules to form two hydrogen bonds simultaneously

\begin{tabular}{|c|c|c|}
\hline Complex & $\mathbf{O}_{\mathbf{c}}$ & $\mathbf{O}_{\mathrm{f}}$ \\
\hline [Gd(TETA)] & $17.3 \%$ & $9.7 \%$ \\
\hline$\left[\mathrm{Gd}(\mathrm{DOTA})\left(\mathrm{H}_{2} \mathrm{O}\right)\right]^{-}$ & $34.5 \%$ & $10.3 \%$ \\
\hline$[\mathrm{Gd}(\mathrm{DOTP})]^{5-}$ & $92.0 \%$ & $22.4 \%$ \\
\hline$\left[\mathrm{Gd}(\mathrm{DTPA})\left(\mathrm{H}_{2} \mathrm{O}\right)\right]^{2-}$ & $54.8 \%$ & $27.1 \%$ \\
\hline [Gd(DTPA-BMA) $\left.\left(\mathrm{H}_{2} \mathrm{O}\right)\right]$ & $49.4 \%$ & $14.0 \%$ \\
\hline
\end{tabular}


Table 8. Hydrogen bonding probability for the inner-sphere water molecule

Complex

$\left[\mathbf{G d}(\text { DOTA })\left(\mathrm{H}_{2} \mathrm{O}\right)\right]^{-} \quad 13.8 \%$

$\left[\mathbf{G d}(\mathrm{DTPA})\left(\mathrm{H}_{2} \mathrm{O}\right)\right]^{2-} \quad 30.3 \%$

[Gd(DTPA-BMA)(H $\left.\left(\mathrm{H}_{2} \mathrm{O}\right)\right] \quad 21.4 \%$ 
Table 9. Electronic relaxation and diffusion parameters used in the simulation of NMRD profiles

\begin{tabular}{|c|c|c|c|c|c|c|}
\hline Complex & $\begin{array}{c}\Delta^{2} \\
{\left[10^{19} \mathrm{~s}^{-2}\right]}\end{array}$ & $\begin{array}{c}\tau_{v} \\
{[\mathrm{ps}]}\end{array}$ & $\delta g^{2}$ & $\begin{array}{c}\tau_{R} \\
{[\mathrm{ps}]}\end{array}$ & $\begin{array}{c}D_{G d H} \\
{\left[10^{-10} \mathrm{~m}^{-2} \mathrm{~s}^{-1}\right]}\end{array}$ & $\begin{array}{l}a_{G d H} \\
{[\AA]}\end{array}$ \\
\hline$[\text { Gd(TETA) }]^{-[a]}$ & 9 & 16 & 0 & - & - & - \\
\hline$\left[\mathrm{Gd}(\mathrm{DOTA})\left(\mathrm{H}_{2} \mathrm{O}\right)\right]^{-[\mathrm{b}]}$ & 1.6 & 11 & 0.019 & 77 & 20.2 & 3.5 \\
\hline$[G d(D O T P)]^{5-[a]}$ & 0.9 & 11 & 0.019 & 77 & - & - \\
\hline$\left[\operatorname{Gd}(\mathrm{DTPA})\left(\mathrm{H}_{2} \mathrm{O}\right)\right]^{2-[\mathrm{b}]}$ & 4.6 & 25 & 0.012 & 58 & 20 & 3.5 \\
\hline$\left[\operatorname{Gd}(\mathbf{D T P A}-\mathrm{BMA})\left(\mathrm{H}_{2} \mathrm{O}\right)\right]^{[\mathrm{b}]}$ & 4.1 & 25 & 0.008 & 66 & 23 & 3.5 \\
\hline
\end{tabular}

${ }^{[a]}$ : electronic parameters from fit to the experimental NMRD data.

${ }^{[b]}$ : parameters from ref. [27] 



\section{Supplementary material}

I. $g_{O X}$ and $g_{N X}$ for macrocyclic ligand complexes
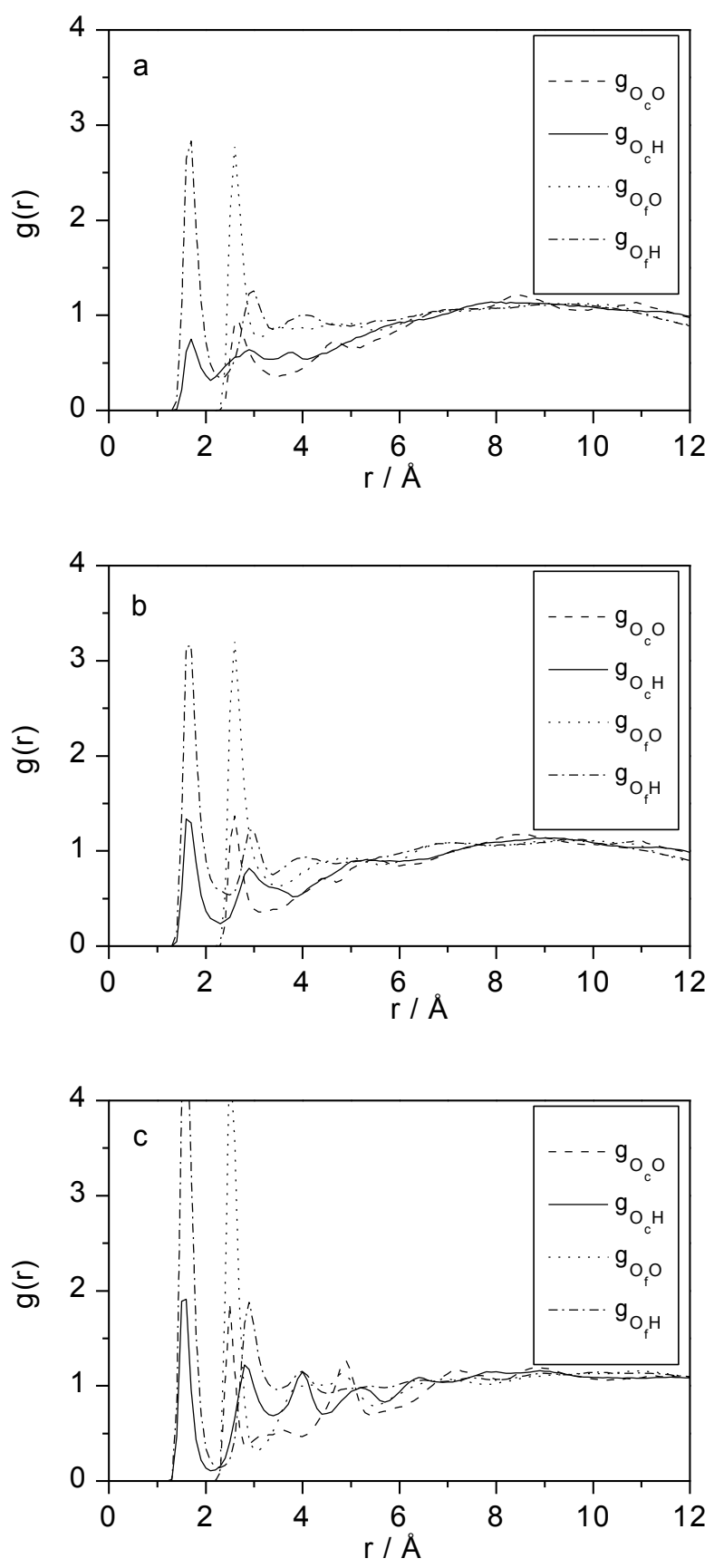

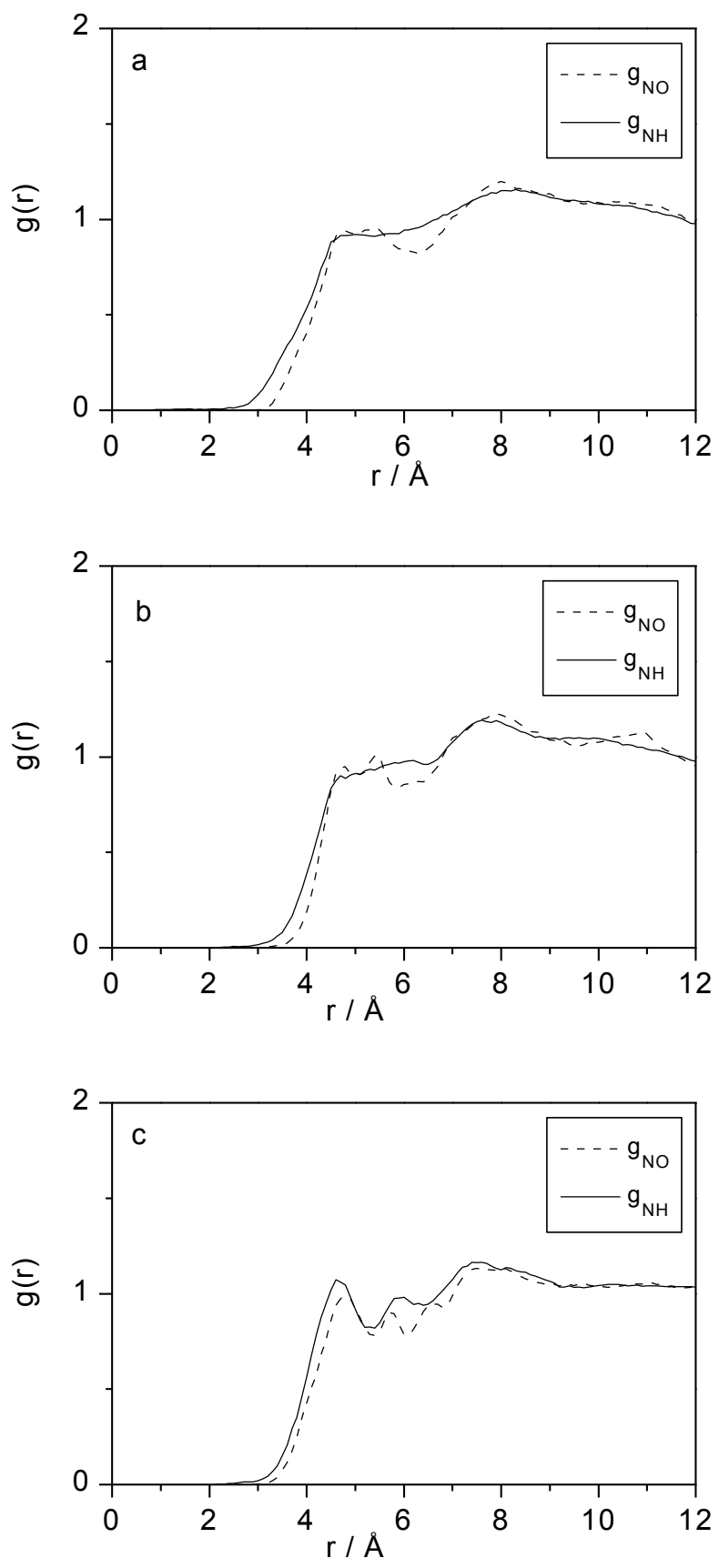

a: [Gd(TETA)]

b: $\left[\mathrm{Gd}(\mathrm{DOTA})\left(\mathrm{H}_{2} \mathrm{O}\right)\right]^{-}$

c: $[\mathrm{Gd}(\mathrm{DOTP})]^{5}$ 
